BNL-113498-2017-JA

\title{
Manipulating the Rate-Limiting Step in Water Oxidation Catalysis by Ruthenium Bipyridine-Dicarboxylate Complexes
}

\author{
David W. Shaffer, Yan Xie, David J. Szalda, Javier J. Concepcion
}

Submitted to Inorganic Chemistry

November 2016

Chemistry Department

Brookhaven National Laboratory

\author{
U.S. Department of Energy \\ USDOE Office of Science (SC), \\ Basic Energy Sciences (BES) (SC-22)
}

Notice: This manuscript has been authored by employees of Brookhaven Science Associates, LLC under Contract No. DE- SC0012704 with the U.S. Department of Energy. The publisher by accepting the manuscript for publication acknowledges that the United States Government retains a non-exclusive, paid-up, irrevocable, world-wide license to publish or reproduce the published form of this manuscript, or allow others to do so, for United States Government purposes. 


\section{DISCLAIMER}

This report was prepared as an account of work sponsored by an agency of the United States Government. Neither the United States Government nor any agency thereof, nor any of their employees, nor any of their contractors, subcontractors, or their employees, makes any warranty, express or implied, or assumes any legal liability or responsibility for the accuracy, completeness, or any third party's use or the results of such use of any information, apparatus, product, or process disclosed, or represents that its use would not infringe privately owned rights. Reference herein to any specific commercial product, process, or service by trade name, trademark, manufacturer, or otherwise, does not necessarily constitute or imply its endorsement, recommendation, or favoring by the United States Government or any agency thereof or its contractors or subcontractors. The views and opinions of authors expressed herein do not necessarily state or reflect those of the United States Government or any agency thereof. 


\section{Manipulating the Rate-Limiting Step in Water Oxidation Catalysis by Ruthenium Bipyridine- Dicarboxylate Complexes}

David W. Shaffer, Yan Xie, David J. Szalda, Javier J. Concepcion*

Chemistry Division, Brookhaven National Laboratory, Upton, NY 11973-5000. ${ }^{\ddagger}$ Department of Natural Sciences, Baruch College, CUNY, New York, New York 10010.

Keywords: water oxidation; oxo-oxo coupling; bimolecular; inverse KIE; single-site

In order to gain a deeper mechanistic understanding of water oxidation by [(bda)Ru(L) $)_{2}$ catalysts (bdaH $\mathrm{H}_{2}=$ [2,2'-bipyridine $]-6,6$ '-dicarboxylic acid; $\mathrm{L}=$ pyridine-type ligand), a series of modified catalysts with one and two trifluoromethyl groups in the 4-position of the bda ${ }^{2-}$ ligand were synthesized and studied using stopped-flow kinetics. The additional $-\mathrm{CF}_{3}$ groups increased the oxidation potentials for the catalysts and enhanced the rate of electrocatalytic water oxidation at low pH. Stopped-flow measurements of cerium(IV)-driven water oxidation at $\mathrm{pH} 1$ revealed two distinct kinetic regimes depending on catalyst concentration. At relatively high catalyst concentration (ca. $\geq 10^{-4} \mathrm{M}$ ), the rate determining step (RDS) was a proton-coupled oxidation of the catalyst by cerium(IV) with direct kinetic isotope effects (KIE $>1$ ). At low catalyst 
concentration (ca. $\leq 10^{-6} \mathrm{M}$ ), the RDS was a bimolecular step with $k_{\mathrm{H}} / k_{\mathrm{D}} \sim 0.8$. The results support a catalytic mechanism involving coupling of two catalyst molecules. The rate constants for both RDSs were determined for all six catalysts studied. The presence of $-\mathrm{CF}_{3}$ groups had inverse effects on the two steps, with the oxidation step being fastest for the unsubstituted complexes and the bimolecular step being faster for the most electron-deficient complexes. Though the axial ligands studied here did not significantly affect the oxidation potentials of the catalysts, the nature of the ligand was found to be important not only in the bimolecular step, but also in facilitating electron transfer from the metal center to the sacrificial oxidant.

\section{Introduction}

The development of alternative energy sources requires the concomitant development of efficient energy storage solutions. In the last decade, research has blossomed in battery technologies and other forms of energy storage, but chemical bonds remain the ideal choice in terms of the required worldwide scale, particularly when it comes to transportation. Among the most simple and attractive systems is the splitting of water into hydrogen and oxygen, which can later be recombined in fuel cells to release the stored energy. Efficient water splitting requires highly active and robust catalysts for both hydrogen and oxygen generation. The performance of molecular catalysts for oxygen evolution $\left(4 \mathrm{e}^{-} / 4 \mathrm{H}^{+}\right.$process) lags behind those for hydrogen evolution $\left(2 \mathrm{e}^{-} / 2 \mathrm{H}^{+}\right)$in terms of rate, robustness, and efficiency. ${ }^{1}$

From the mechanistic perspective, there are two major classifications of water oxidation catalysts based on how the key O-O bond formation step takes place: single-site catalysts, involving water nucleophilic attack at a single metal-oxo fragment (WNA), and two-site catalysts, where the O-O bond is formed via radical coupling interaction of two metal-oxo moieties with oxyl radical character (I2M). ${ }^{2,3}$ Both of these mechanisms can be followed by a 
variety of catalyst types, and it is important to make a clear distinction between the mechanistic classification (single-site WNA vs two-site I2M) and the nuclearity of the catalyst (mononuclear, dinuclear/multinuclear, etc.). The single-site pathway has been proposed for mononuclear, ${ }^{4-7}$ multinuclear, ${ }^{8-10}$ and nanoparticle ${ }^{11,12}$ catalysts. In the single-site mechanism, a water molecule attacks an electron-deficient metal-oxo species with simultaneous proton transfer to a hydrogenbound proton acceptor, generating an intermediate metal-hydroperoxide, Scheme $1 .{ }^{13-15}$ The proton acceptor can be another water molecule, ${ }^{16,17}$ the basic form of a buffer, ${ }^{14,18}$ a strategically positioned base, ${ }^{19}$ or another nearby metal-oxo moiety, as is the case for the ruthenium "blue dimer”. ${ }^{8-10}$ Single-site catalysts typically display H/D kinetic isotope effects if the O-O bond formation is rate-limiting and the overall rate of water oxidation is sensitive to both the nature $\left(\mathrm{p} K_{\mathrm{a}}\right)$ and concentration of the buffer.

(A) Mononuclear catalyst:

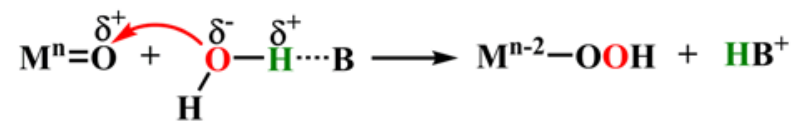

(B) Dinuclear catalyst:

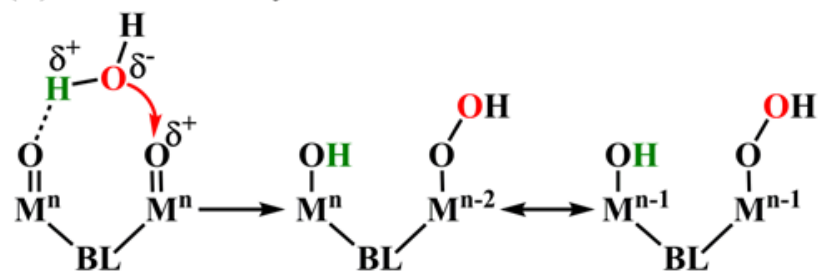

Scheme 1. O-O bond formation via single-site water nucleophilic attack (WNA) pathways for (A) mononuclear catalysts and (B) dinuclear catalysts. BL represents a bridging ligand.

In the second class, the interaction of two metal-oxyl radicals (I2M) results in O-O coupling to form a peroxo bridge between the two metal centers, Scheme 2. These two metals can be a part of the same molecule in a multinuclear complex, ${ }^{20}$ a cluster, ${ }^{21}$ or a nanoparticle, ${ }^{22}$ or two independent molecules, ${ }^{4}$ as reported for $\left[(\mathrm{bda}) \mathrm{Ru}(\mathrm{L})_{2}\right]$ (vide infra). ${ }^{23}$ When the O-O bond 
formation is rate-limiting, catalysts in this class should not display H/D kinetic isotope effects and the overall rate of water oxidation should be insensitive to both the nature and concentration of the buffer.

(A) Mononuclear catalyst:

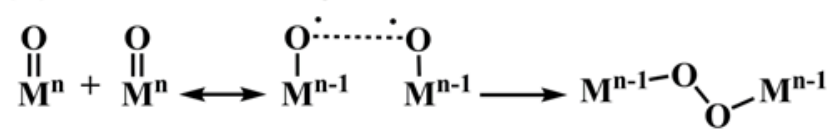

(B) Dinuclear catalyst:

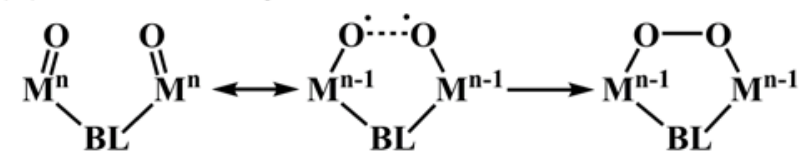

Scheme 2. O-O bond formation via radical coupling interaction of two metal-oxo/oxyl fragments (I2M) for (A) mononuclear and (B) dinuclear catalysts. BL represents a bridging ligand.

Ruthenium polypyridyl complexes hold a special place in the landscape of molecular water oxidation catalysts (WOCs). Not only is the first molecular WOC, the blue dimer, a ruthenium polypyridyl complex, but they are among the most widely studied, with new developments continuing to be made. ${ }^{8,24-26}$ A relatively recent advance was the introduction of carboxylate groups on bipyridine to provide a planar, tetradentate, dianionic, bipyridyl-dicarboxylate (bda ${ }^{2-}$ ) ligand. Ruthenium complexes with the formula [(bda)Ru(L $\left.)_{2}\right]$, where $\mathrm{L}$ is a neutral pyridinebased donor, were first reported by the Sun group in 2009, and WOCs of this type remain among the fastest to date. ${ }^{27,}{ }^{28}$ Since its initial report, [(bda)Ru(L) 2 ] complexes have attracted a great deal of interest from the Sun group ${ }^{23}$ and others, ${ }^{29-34}$ and related systems are an active area of research. $^{19,35-39}$

Several mechanisms for water oxidation by $\left[(\mathrm{bda}) \mathrm{Ru}(\mathrm{L})_{2}\right]$ have been proposed, which differ in the nature of the O-O bond-forming step, shown in Scheme 3. A common thread among the proposed mechanisms is that the majority of oxidation steps proceed via proton-coupled electron-transfer (PCET), a key consideration for realizing the remarkably low overpotentials of 
these catalysts. Initial reports from Sun and coworkers proposed a mechanism for cerium-driven water oxidation that proceeds through radical O-O coupling between two ruthenium(V)-oxo complexes, labelled $\mathrm{A}$ in Scheme 3 and corresponding to $\mathrm{A}$ in Scheme $2 .^{28}$ The rate-determining step (RDS) under catalytic conditions was proposed to be a bimolecular coupling of two $\mathrm{Ru}^{\mathrm{V}}=\mathrm{O}$ molecules for [(bda)Ru(pic) $)_{2}$ (pic is 4-picoline). Due to a faster bimolecular step, the isoquinoline complex [(bda)Ru(isq) $)_{2}$ ] was proposed to be rate-limited by the oxidation of the resulting $\left[\mathrm{Ru}^{\mathrm{IV}}-\mathrm{O}-\mathrm{O}-\mathrm{Ru}^{\mathrm{IV}}\right]$ dimer after $\mathrm{O}-\mathrm{O}$ coupling. This was based on UV-Vis absorption spectral-fitting and stopped-flow kinetic studies with sub-micromolar catalyst concentrations.

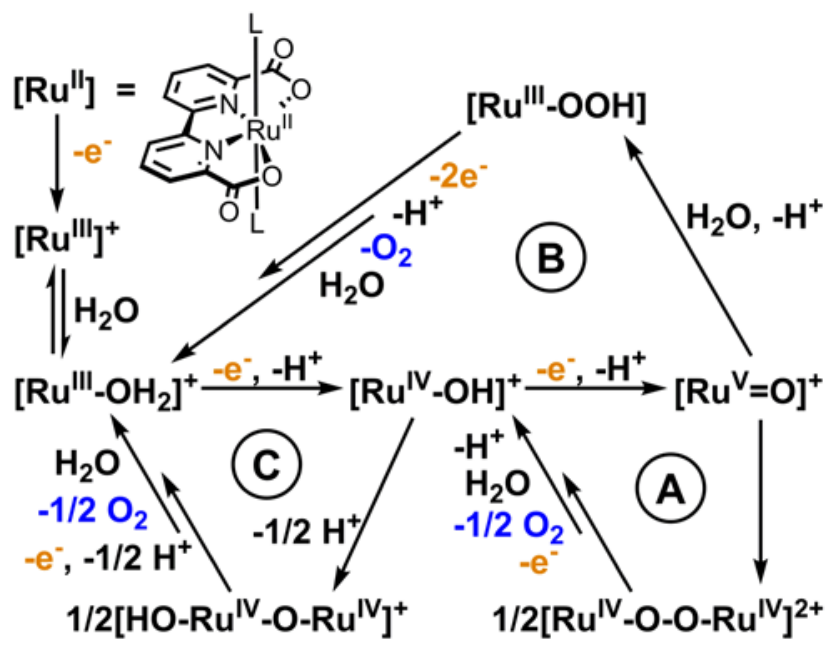

Scheme 3. Proposed mechanisms for water oxidation catalyzed by [(bda)Ru(L) $)_{2}$ complexes.

The Meyer group has proposed involvement of a water nucleophilic attack mechanism based on solution and surface electrochemical experiments, labelled B in Scheme 3 and corresponding to $\mathrm{A}$ in Scheme $1 .^{30-32}$ Depending on the conditions, the RDS was proposed to be the O-O bond formation step or proton-coupled oxidation of $\mathrm{Ru}^{\mathrm{IV}}-\mathrm{OH}$ to $\mathrm{Ru}^{\mathrm{V}}=\mathrm{O}$. Evidence for this mechanism include an observed first-order dependence on catalyst concentration, rate enhancement with higher concentration of base, and slow electron transfer for the higher oxidation states of ruthenium. 
Support for a third mechanism involving blue-dimer-like Ru-O-Ru intermediates was recently reported by our group, pathway C in Scheme $3 .^{33}$ Spectroelectrochemical experiments and electrochemical comparison of solution and surface-bound catalysts suggested the formation of a $\mu$-oxo dimer from two $\mathrm{Ru}^{\mathrm{IV}}-\mathrm{OH}$ molecules. In this mechanism, the dimerization step involves proton-loss and precedes O-O bond formation. Because the O-O bond is formed after the RDS, it is difficult to determine the nature of this step, specifically whether it proceeds through a singlesite nucleophilic attack like the blue dimer (Scheme 1, B), ${ }^{8-10}$ or whether terminal and bridging oxygen atoms come together (a variation of Scheme 2, B). It is also possible that the formation of a Ru-O-Ru dimer requires loss of one of the axial ligands, in which case the active catalytic cycle may not involve cycling through the same monomeric $\left[(\mathrm{bda}) \mathrm{Ru}(\mathrm{L})_{2}\right]$ intermediates.

The determination of the rate law for catalysis under a given set of conditions may help to establish the operating mechanism. Of the three mechanistic pathways in Scheme 3, A and C involve bimolecular coupling between two catalyst molecules. Therefore, a second-order dependence on catalyst concentration would rule out pathway B. On the other hand, pathway B is the only one of the three that may exhibit first-order behavior with respect to catalyst while having zero-order dependence on oxidant. All of the proposed mechanisms involve protoncoupled oxidation steps. In this work, we report stopped-flow kinetic data for the cerium(IV)driven homogenous water oxidation by $\left[(\mathrm{R}-\mathrm{bda}) \mathrm{Ru}(\mathrm{L})_{2}\right]$ catalysts that supports a mechanism involving proton-coupled oxidation steps and a bimolecular step. This could correspond to Pathway C or Pathway A. Furthermore, we find clear concentration-dependent switching of the rate-determining step between a proton-coupled oxidation and a bimolecular step, which is consistent with the seeming discrepancies observed in the literature between electrochemical (millimolar catalyst concentrations) and stopped-flow absorption studies (sub-micromolar 
catalyst concentrations). In addition, we observe a direct kinetic isotope effect (KIE) in the high concentration regime and an inverse KIE in the low concentration regime. The latter is not straightforward in the context of a radical O-O coupling as the rate limiting bimolecular step observed at low catalyst concentrations.

Towards reaching a deeper understanding of the factors controlling the efficacy of these catalysts we examine here a series of catalysts with zero, one, and two electron-withdrawing trifluoromethyl groups on the bda ${ }^{2-}$ ligand. Sun ${ }^{40,41}$ and others ${ }^{29,42}$ have shown that changing the nature of the axial pyridine donors can significantly affect the rate of chemical and photochemical catalysis. However, if these catalysts indeed proceed through a bimolecular step facilitated by $\pi$-stacking interactions, it can be difficult to parse the electronic and $\pi$-stacking aspects of axial ligand modification. In addition, the active site for water oxidation is in the equatorial plane occupied by the $\mathrm{Ru}(\mathrm{bda})$ framework. Therefore, modification of the $\mathrm{bda}^{2-}$ backbone is expected to have a significant electronic effect on the metal center, but should be relatively innocent in terms of intermolecular interactions. In spite of this, there has been relatively limited study of variations in the plane of the bda ${ }^{2-}$ ligand. ${ }^{43,44}$ In studies of another WOC, [(bpy)Ru(tpy) $\left.\mathrm{OH}_{2}\right]^{2+}$, Berlinguette and coworkers showed that substituents trans to the complex's active site had a more pronounced effect than those cis to the active site on oxidation potentials, catalytic rate, and robustness. ${ }^{45}$ Furthermore, DFT calculations and X-ray crystallography show that electronic and structural changes upon oxidation of the [(bda)Ru(L) 2 ] platform are primarily localized in the plane containing the ruthenium center and $\mathrm{bda}^{2-}$ ligand. ${ }^{27}$, 33, 46 Thus, the variation of substituents in the bda $^{2-}$ ligand is expected to have a pronounced effect on the catalytic activity of the complexes. We present here experimental rate constants for 
both the slow oxidation step and the bimolecular coupling step, each showing different trends with respect to the number of electron-withdrawing trifluoromethyl groups on the bda ${ }^{2-}$ ligand.

\section{Results}

Synthesis and Characterization of $(\mathbf{R}-\mathbf{b d a}) \mathbf{R u}(\mathbf{L})_{2}$. The 4,4'-CF $-\mathrm{CdaH}_{2}$ ligand $\left(4,4^{\prime}-\mathrm{CF}_{3}{ }^{-}\right.$ bda $^{2-}$ is $6,6^{\prime}$-dicarboxy-4,4'-bistrifluoromethyl-2,2'-bipyridine) was synthesized from the commercially available 2-chloro-6-methyl-4-trifluoromethylpyridine, Scheme 4. Treatment with hydriodic acid effected replacement of the chlorine for iodine, ${ }^{47}$ allowing for subsequent Ullmann coupling to provide 6,6'-dimethyl-4,4'-bis(trifluoromethyl)-2,2'-bipyridine. ${ }^{48}$ Oxidation of the methyl groups with dichromate provided the free diacid 4,4'- $\mathrm{CF}_{3}-\mathrm{bdaH}_{2}$ as a white solid in $76 \%$ yield. ${ }^{49}$ Characterization is consistent with a previously reported procedure. ${ }^{50}$

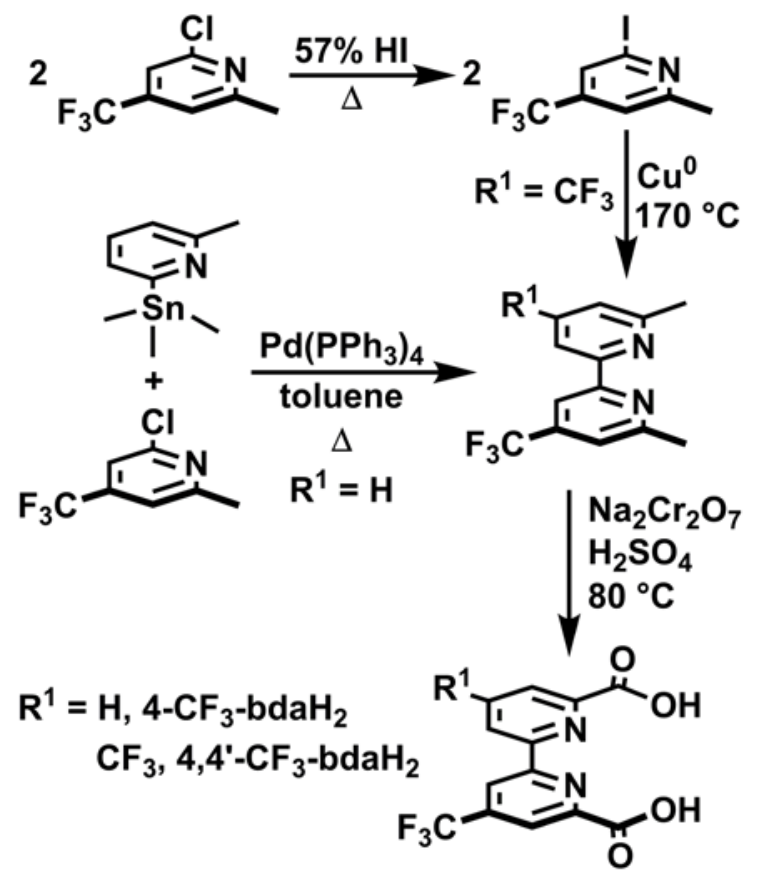

Scheme 4. Synthesis of 4,4'- $-\mathrm{CF}_{3}-\mathrm{bdaH} \mathrm{H}_{2}$ and 4- $\mathrm{CF}_{3}-\mathrm{bdaH}_{2}$.

The nonsymmetric ligand 4- $\mathrm{CF}_{3}-\mathrm{bdaH}_{2}\left(4,-\mathrm{CF}_{3}-\mathrm{bda}^{2-}=6,6^{\prime}\right.$-dicarboxy-4-trifluoromethyl-2,2'bipyridine) was synthesized using Stille coupling of 2-methylpyridyl and 2-methyl-4- 
trifluoromethylpyridyl units followed by dichromate oxidation of the methyl groups, Scheme 4. Coupling of 2-methyl-6-(trimethylstannyl)pyridine ${ }^{51}$ with commercially available 2-chloro-6methyl-4-(trifluoromethyl)pyridine was mediated by palladium(0) tetrakis(triphenylphosphine) in refluxing toluene. Pure 6,6'-dimethyl-4-trifluoromethyl-2,2'-bipyridine was obtained in 67\% yield after an acid extraction followed by precipitation after neutralization. ${ }^{52}$ Oxidation with sodium dichromate in sulfuric acid provided $4-\mathrm{CF}_{3}-\mathrm{bdaH}_{2}$ in $84 \%$ yield.

The synthesis of the complexes [(R-bda)Ru(pic) $)_{2}$ and [(R-bda)Ru(isq) $)_{2}$ (pic is 4-picoline; isq is isoquinoline) was achieved by reaction of $\mathrm{R}-\mathrm{bdaH}_{2}$ with $\left[\left(\mathrm{C}_{6} \mathrm{H}_{6}\right) \mathrm{RuCl}_{2}\right]_{2}$, triethylamine, and the appropriate axial ligand, Scheme 5. The benzene-chloro ruthenium(II) dimer was first refluxed in methanol with the free ligand under argon, presumably producing $\left[\left(\kappa_{2}-\mathrm{CF}_{3^{-}}\right.\right.$ bdaH $\left.\left._{2}\right) \mathrm{RuCl}\left(\mathrm{C}_{6} \mathrm{H}_{6}\right)\right][\mathrm{Cl}]$ in situ. ${ }^{53,54}$ Addition of excess triethylamine and axial ligand and further reflux provided a deep burgundy solution. In the case of $\left[\left(4,4^{\prime}-\mathrm{CF}_{3}-\mathrm{bda}\right) \mathrm{Ru}(\mathrm{L})_{2}\right]$, the reaction mixture was filtered, removing a small amount of orange $\mathrm{RuCl}_{2} \mathrm{~L}_{4},{ }^{55}$ and taken to dryness. In the case of $\left[\left(4-\mathrm{CF}_{3}-\mathrm{bda}\right) \mathrm{Ru}(\mathrm{L})_{2}\right]$, which are less soluble in methanol than their symmetrical counterparts, the reaction mixtures were simply reduced to dryness to yield crude product. Column chromatography provided pure $\left[\left(4,4^{\prime}-\mathrm{CF}_{3}-\mathrm{bda}\right) \mathrm{Ru}(\mathrm{pic})_{2}\right]$ (52\% yield), $\left[\left(4,4^{\prime}-\mathrm{CF}_{3^{-}}\right.\right.$ bda)Ru(isq) $)_{2}$ (45\% yield), [(4-CF 3 -bda)Ru(pic) $)_{2}$ (62\% yield), and [(4-CF 3 bda)Ru(isq) $)_{2}$ (72\% yield). 


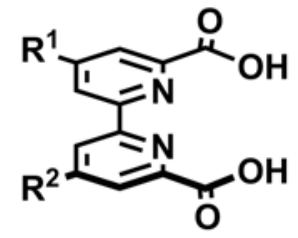

1. $\left[\mathrm{RuCl}_{2}\left(\mathrm{C}_{6} \mathrm{H}_{6}\right)\right]_{2}$

2. L, $\mathrm{NEt}_{3}$

$\mathrm{MeOH}, \Delta$

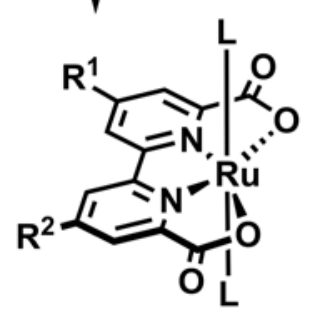<smiles>Cc1ccncc1</smiles>

pic isq

$\mathbf{R}^{1}=\mathbf{R}^{2}=\mathbf{H}:$

[(bda) Ru(L) $\left.)_{2}\right]$

$\mathrm{R}^{1}=\mathrm{H} ; \mathrm{R}^{2}=\mathrm{CF}_{3}$ :

$\left[\left(4-\mathrm{CF}_{3}-\mathrm{bda}\right) \mathrm{Ru}(\mathrm{L})_{2}\right]$

$\mathbf{R}^{1}=\mathbf{R}^{2}=\mathrm{CF}_{3}$ :

$\left[\left(4,4^{\prime}-\mathrm{CF}_{3}-\mathrm{bda}\right) \mathrm{Ru}(\mathrm{L})_{2}\right]$

Scheme 5. Synthesis of [(R-bda)Ru(L)] complexes.

The identities of the products were confirmed by mass spectrometry, X-ray crystallography, and ${ }^{1} \mathrm{H},{ }^{13} \mathrm{C}$, and ${ }^{19} \mathrm{~F}$ NMR. Electrospray ionization mass spectrometry (ESI-MS) confirmed the formulation of the four new complexes, displaying $[\mathrm{M}+\mathrm{H}]^{+}$signals with the expected isotopic distributions for $\left[\left(4,4^{\prime}-\mathrm{CF}_{3}\right.\right.$-bda)Ru(pic) 2 (m/z: 667.0), [(4,4'-CF $-\mathrm{CF}_{3}$-ba)Ru(isq) $]$ (m/z: 739.0), [(4-CF 3 -bda)Ru(pic) 2 (m/z: 598.9), and [(4-CF 3 -bda)Ru(isq) 2 (m/z: 671.0). NMR spectra for $\left[\left(4,4^{\prime}-\mathrm{CF}_{3}\right.\right.$-bda $\left.) \mathrm{Ru}(\mathrm{pic})_{2}\right]$ and $\left[\left(4,4^{\prime}-\mathrm{CF}_{3} \text {-bda)Ru(isq) }\right)_{2}\right.$ are consistent with their $C_{2 v}$ symmetry, having two singlets corresponding to the protons on the $4,4^{\prime}-\mathrm{bda}^{2-}$ backbone, and a single set of resonances for the two equivalent axial ligands. The ${ }^{19} \mathrm{~F}$ NMR spectra for both complexes display a single resonance at $64 \mathrm{ppm}$ corresponding to the $-\mathrm{CF}_{3}$ groups. The reduced symmetry in $\left[\left(4-\mathrm{CF}_{3} \text {-bda)Ru(pic) }\right)_{2}\right]$ and $\left[\left(4-\mathrm{CF}_{3}\right.\right.$ bda $\left.) \mathrm{Ru}(\mathrm{isq})_{2}\right]$ results in $\mathrm{NMR}$ spectra similar to a combination of the corresponding $\mathrm{bda}^{2-}$ and $4,4^{\prime}-\mathrm{CF}_{3}-\mathrm{bda}^{2-}$ complexes. The two axial ligands remain equivalent, but the protons of the $4-\mathrm{CF}_{3}-\mathrm{bda}^{2-}$ backbone are all unique, exhibiting two doublets and a triplet for the unsubstituted ring and two singlets for the $-\mathrm{CF}_{3}$ ring. The purity of 
$\left[\left(4,4^{\prime}-\mathrm{CF}_{3}\right.\right.$-bda $\left.) \mathrm{Ru}(\mathrm{pic})_{2}\right],\left[\left(4,4^{\prime}-\mathrm{CF}_{3}\right.\right.$-bda) $\left.\mathrm{Ru}(\mathrm{isq})_{2}\right]$, and $\left[\left(4-\mathrm{CF}_{3} \mathrm{bda}\right) \mathrm{Ru}(\mathrm{isq})_{2}\right]$ were verified by elemental analysis.

The structure of $\left[\left(4,4^{\prime}-\mathrm{CF}_{3}\right.\right.$-bda $\left.) \mathrm{Ru}(\mathrm{pic})_{2}\right]$ was further confirmed by single-crystal X-ray diffraction analysis of crystals obtained from slow diffusion of $n$-hexane into a $\mathrm{CH}_{2} \mathrm{Cl}_{2}$ solution of the complex. Figure 1 shows the structure of $\left[\left(4,4^{\prime}-\mathrm{CF}_{3} \text {-bda)Ru(pic) }\right)_{2}\right]$ and Table 1 lists selected bond distances alongside those for $\left[(\mathrm{bda}) \mathrm{Ru}(\mathrm{pic})_{2}\right] .{ }^{27}$ There are only minor structural differences between the two complexes, the most significant being in the ruthenium-bda distances, which are slightly shortened by up to $0.03 \AA$ in the $-\mathrm{CF}_{3}$ substituted complex. The crystal structure of $\left[\left(4,4^{\prime}-\mathrm{CF}_{3}\right.\right.$-bda $\left.) \mathrm{Ru}(\mathrm{isq})_{2}\right]$ was also determined and is similar to the picoline congener (see Figure S14 in the Supporting Information).

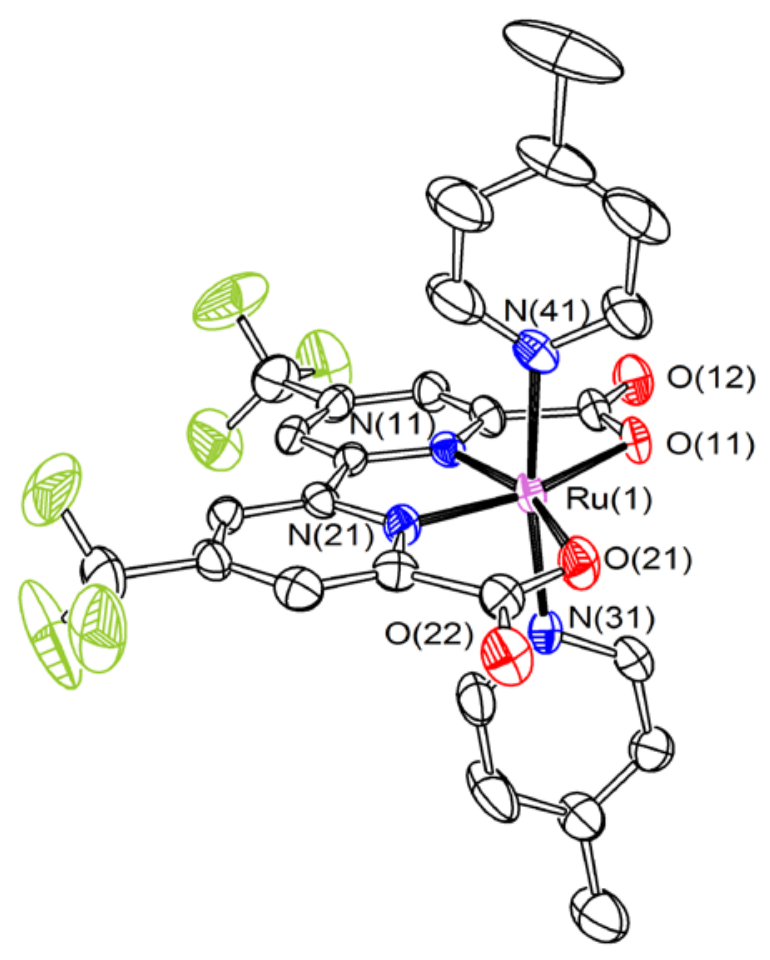

Figure 1. ORTEP diagram of $\left[\left(4,4^{\prime}-\mathrm{CF}_{3}-\mathrm{bda}\right) \mathrm{Ru}(\mathrm{pic})_{2}\right]$. Thermal ellipsoids shown at $50 \%$ probability. Hydrogen atoms and cocrystallized hexane molecule omitted for clarity. 
Table 1. Selected bond distances $(\AA)$ and angle (deg) for $\left[(\mathrm{bda}) \mathrm{Ru}(\mathrm{pic})_{2}\right]^{27}$ and $\left[\left(4,4^{\prime}-\mathrm{CF}_{3}\right.\right.$ bda)Ru(pic) $)_{2}$. Atom numbers modified for clarity of comparison.

\begin{tabular}{|c|c|c|}
\hline Bond/Angle & {$\left[(\mathbf{b d a}) \mathbf{R u}^{\mathrm{II}}(\mathbf{p i c})_{2}\right]$} & {$\left[\left(4,4^{\prime}-C_{3}-b^{-b d a}\right) R^{I I}(p i c)_{2}\right]$} \\
\hline $\mathrm{Ru}-\mathrm{O} 1_{\mathrm{COO}}$ & $2.216(7)$ & $2.187(5)$ \\
\hline $\mathrm{Ru}-\mathrm{O} 2_{\mathrm{COO}}$ & $2.172(6)$ & $2.168(5)$ \\
\hline $\mathrm{Ru}-\mathrm{N} 1_{\text {bpy }}$ & $1.949(7)$ & $1.927(6)$ \\
\hline Ru-N2 ${ }_{\text {bpy }}$ & $1.914(6)$ & $1.910(4)$ \\
\hline $\mathrm{Ru}-\mathrm{N} 1_{\text {pic }}$ & $2.070(6)$ & $2.082(6)$ \\
\hline $\mathrm{Ru}-\mathrm{N} 2_{\text {pic }}$ & $2.084(6)$ & $2.090(6)$ \\
\hline$\angle \mathrm{O}-\mathrm{Ru}-\mathrm{O}$ & $123.0(2)$ & 120.97(17) \\
\hline
\end{tabular}

Electrochemical Characterization and Catalytic Water Oxidation. Electrochemical analysis of $\left[\left(4-\mathrm{CF}_{3}-\mathrm{bda}\right) \mathrm{Ru}(\mathrm{L})_{2}\right]$ and $\left[\left(4,4^{\prime}-\mathrm{CF}_{3}-\mathrm{bda}\right) \mathrm{Ru}(\mathrm{L})_{2}\right]$ revealed considerable anodic shifts in the oxidation potentials with respect to the parent $\mathrm{bda}^{2-}$ complexes. Figure 2 shows cyclic voltammograms (CVs) and square wave voltammograms (SWVs) for [(bda)Ru(pic) 2 , [(4-CF $3^{-}$ bda)Ru(pic $\left.)_{2}\right]$, and $\left[\left(4,4^{\prime}-\mathrm{CF}_{3} \text {-bda)Ru(pic) }\right)_{2}\right.$ at $\mathrm{pH} 1$ and Table 2 lists oxidation potentials for [(R-bda)Ru(L $\left.)_{2}\right]$ at $\mathrm{pH}$ 1. Except for some differences discussed below, the electrochemical behavior of the isoquinoline complexes is similar to the picoline complexes and the corresponding data is shown in Figures S3-S8 in the Supporting Information. Electrochemical data were collected in aqueous solution with the addition of $10 \% \mathrm{CH}_{3} \mathrm{CN}$ to promote the solubility of the complexes. ${ }^{56}$ Like the parent complexes, ${ }^{28,} 30,57$ the trifluoromethyl derivatives exhibit two oxidations before the onset of electrocatalytic water oxidation. As shown in Figure 2, the introduction of one trifluoromethyl group increases the $\mathrm{Ru}^{\mathrm{III} / \mathrm{II}}$ oxidation potential by $70-80$ $\mathrm{mV}$, while the $\mathrm{Ru}^{\mathrm{IV} / \mathrm{III}}$ couple is affected by just $30 \mathrm{mV}$. Distortion of the $\mathrm{Ru}^{\mathrm{IV} / \mathrm{III}}$ wave arises from kinetic inhibition, which has been examined in detail for other monomeric ruthenium 
complexes. $^{58}$ The second trifluoromethyl group effects a further shift of $80-90 \mathrm{mV}$ in the $\mathrm{Ru}^{\mathrm{III/II}}$ potential and 0-20 mV in the $\mathrm{Ru}^{\mathrm{IV} / \mathrm{III}}$ potential. This equates to a $90-115 \mathrm{mV}$ increase in oxidizing power (per electron) for the doubly oxidized complex.

Table 2. Oxidation potentials (V vs NHE) for $\left[(\mathrm{R}-\mathrm{bda}) \mathrm{Ru}(\mathrm{L})_{2}\right]$ complexes at $\mathrm{pH} 1(0.10 \mathrm{M}$ $\mathrm{HNO}_{3}$ ) with $10 \% \mathrm{MeCN}$.

\begin{tabular}{|c|c|c|}
\hline Complex & $\mathbf{R u}{ }^{\mathrm{III} / \mathrm{II}}$ & $\mathbf{R u}^{\mathrm{IV} / I I I}$ \\
\hline$\left[(\mathrm{bda}) \mathrm{Ru}(\mathrm{pic})_{2}\right]$ & 0.85 & 1.10 \\
\hline [(bda)Ru(isq) $\left.)_{2}\right]$ & 0.86 & 1.09 \\
\hline$\left[\left(4-\mathrm{CF}_{3}\right.\right.$-bda $\left.) \mathrm{Ru}(\mathrm{pic})_{2}\right]$ & 0.92 & 1.13 \\
\hline$\left[\left(4-\mathrm{CF}_{3} \text {-bda)Ru(isq) }\right)_{2}\right]$ & 0.94 & 1.12 \\
\hline$\left[\left(4,4^{\prime}-\mathrm{CF}_{3}-\mathrm{bda}\right) \mathrm{Ru}(\mathrm{pic})_{2}\right]$ & 1.00 & 1.13 \\
\hline$\left[\left(4,4^{\prime}-\mathrm{CF}_{3}\right.\right.$-bda $\left.) \mathrm{Ru}(\text { isq })_{2}\right]$ & 1.03 & 1.15 \\
\hline
\end{tabular}
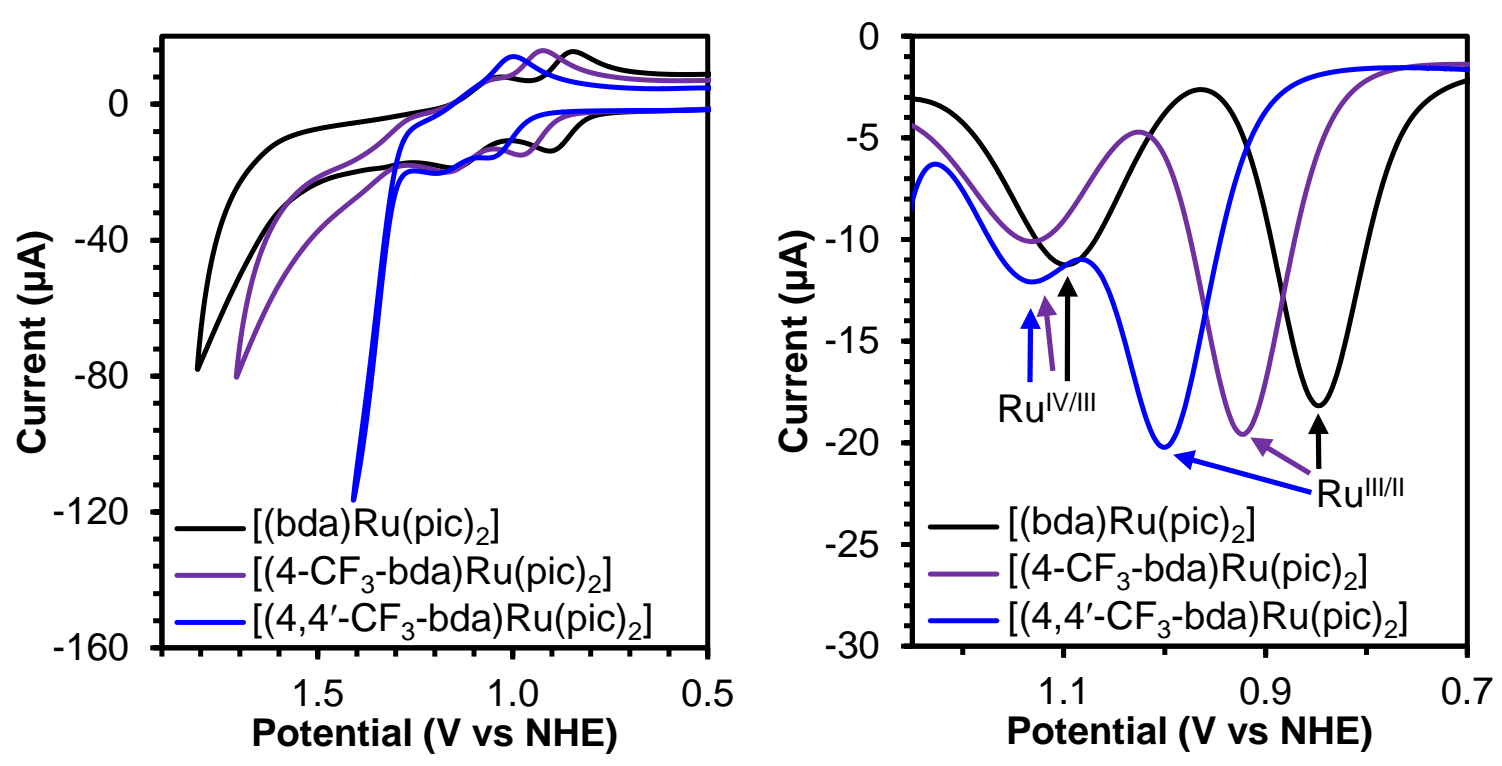

Figure 2. Cyclic voltammograms (left) and differential pulse voltammograms (right) for

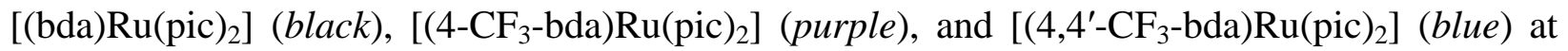
pH 1.0 (0.10 $\mathrm{M} \mathrm{HNO}_{3}$ with $\left.10 \% \mathrm{MeCN}\right)$. 
Scanning further anodically, all three complexes exhibit a catalytic wave positive of the ruthenium(IV/III) couple, corresponding to the oxidation of water to $\mathrm{O}_{2}$. For the parent [(bda) Ru(pic) ${ }_{2}$ ] catalyst, the catalytic current slowly grows as the potential is increased, beginning around $1.3 \mathrm{~V}$ (all potentials reported versus $\mathrm{NHE})$. The catalytic current for $\left[\left(4-\mathrm{CF}_{3}-\right.\right.$ bda) $\left.\mathrm{Ru}(\mathrm{pic})_{2}\right]$ is slightly higher, while the catalytic wave for $\left[\left(4,4^{\prime}-\mathrm{CF}_{3}-\mathrm{bda}\right) \mathrm{Ru}(\mathrm{pic})_{2}\right]$ is drastically steeper than the more electron-rich complexes. Interestingly, while the isoquinoline complexes exhibit the same trend, the differences between the three catalysts are much less significant, with all three catalytic waves beginning at $1.22 \mathrm{~V}$ (see Figure S3 in the Supporting Information).

As the $\mathrm{pH}$ is increased, the $\mathrm{Ru}^{\mathrm{III/II}}$ and $\mathrm{Ru}^{\mathrm{IV} / I I I}$ couples merge into a single wave, and the order of the rate of catalysis based on catalytic currents between the R-bda ${ }^{2-}$ variants is reversed. In $\mathrm{pH}$ 3.9 acetate buffer, a single broad, but reversible, 2-electron wave is observed before the onset of catalysis (see Figures S5, S6, and S9 in the Supporting Information). The [(R-bda)Ru(pic) $\left.{ }_{2}\right]$ catalysts obey the same trend as at $\mathrm{pH} 1$, while the three [(R-bda) $\left.\mathrm{Ru}(\mathrm{isq})_{2}\right]$ catalysts have about the same catalytic activity. In $\mathrm{pH} 7.2$ phosphate buffer, the 2-electron oxidations are no longer reversible, except for the more easily oxidized unsubstituted [(bda)Ru(L) $)_{2}$ complexes (see Figures S7-S9 in the Supporting Information). Interestingly, the trend in catalyst activity is reversed at $\mathrm{pH} 7$ with respect to the $\mathrm{R}-\mathrm{bda}^{2-}$ substituent compared to that at lower $\mathrm{pH}$, with the parent $\left[(\mathrm{bda}) \mathrm{Ru}(\mathrm{L})_{2}\right]$ catalysts exhibiting greater catalytic current. The isoquinoline complexes outperform the picoline complexes at all $\mathrm{pH}$ values.

Kinetics of [(R-bda)Ru(L $\left.)_{2}\right]$-Mediated Water Oxidation. To gain further understanding of the mechanism for water oxidation catalysis, the kinetics of $\left[(\mathrm{R}-\mathrm{bda}) \mathrm{Ru}(\mathrm{L})_{2}\right]$-catalyzed chemical water oxidation by cerium(IV) was studied using stopped-flow kinetics measurements. A 4.0 
$\mathrm{mM}$ solution of ceric ammonium nitrate in $0.20 \mathrm{M} \mathrm{HClO}_{4}$ was mixed with an equal amount of catalyst solution in 4:1 water/acetonitrile, with catalyst concentrations after mixing ranging from $200 \mu \mathrm{M}$ to $0.39 \mu \mathrm{M}$. The rate of cerium(IV) consumption was monitored using absorption at 360 $\mathrm{nm}$. The reaction order with respect to cerium(IV) is reflected in the resulting plot of [Ce] $v s$ time, revealing either a zero-order (linear consumption) or first-order dependence (logarithmic consumption). Furthermore, the reaction order with respect to catalyst is obtained using the slope from the plot of $-\log \left(d\left[\mathrm{Ce}^{\mathrm{IV}}\right] / d t\right)$ vs $-\log [\mathrm{Ru}]$ (log/log plot), where $d\left[\mathrm{Ce}^{\mathrm{IV}}\right] / d t$ is the initial rate and $[\mathrm{Ru}]$ is the catalyst concentration.

The six catalysts examined display two different kinetic regimes, with rate laws depending on the catalyst concentration: first order in both cerium(IV) and catalyst at higher concentrations and zero order in cerium(IV) and second order in catalyst at lower concentrations. For all of the variants, an exponential decay in cerium(IV) was observed at catalyst concentrations on the order of $10^{-4} \mathrm{M}$, indicating first-order dependence. As the concentrations decrease, a point is reached at which $d\left[\mathrm{Ce}^{\mathrm{IV}}\right] / d t$ is better fit to a linear zero-order dependence. Figure 3 shows plots of $\left[\mathrm{Ce}^{\mathrm{IV}}\right]$ vs time for the first order and zero order regimes with respect to cerium using $\left[\left(4,4^{\prime}-\mathrm{CF}_{3}-\right.\right.$ bda)Ru(pic) $)_{2}$ at $150 \mu \mathrm{M}$ and $12.5 \mu \mathrm{M}$, respectively. Shown in Figure 4, the slopes of the $\log / \log$ plots for $\left[(\mathrm{bda}) \mathrm{Ru}(\mathrm{pic})_{2}\right]$ and $\left[\left(4,4^{\prime}-\mathrm{CF}_{3}\right.\right.$-bda $\left.) \mathrm{Ru}(\mathrm{pic})_{2}\right]$ clearly transition from about 1 at higher concentrations to about 2 at lower concentrations, indicating a change between first-order and second-order dependence on catalyst concentration. Taken together, this data indicates that the rate determining step at relatively higher concentrations involves a reaction between cerium(IV) and the catalyst, presumably oxidation of the catalyst. At lower concentrations, the rate determining step is independent of cerium and bimolecular in catalyst, consistent with the coupling of two catalyst molecules. Analogous behavior has been observed for similar catalysts 
with varying cerium(IV) concentration. ${ }^{59}$ The rate laws for these two regimes are represented by equations 1 and 2, respectively. The catalyst concentration at which the rate determining step changes, represented by the red " $\mathrm{X}$ " in Figure 4, is the value of $[\mathrm{Ru}]$ for which the two rate laws are equal (eq 1 = eq 2) and depends on the rate constants of the two steps (vide infra), as shown in equation 3.
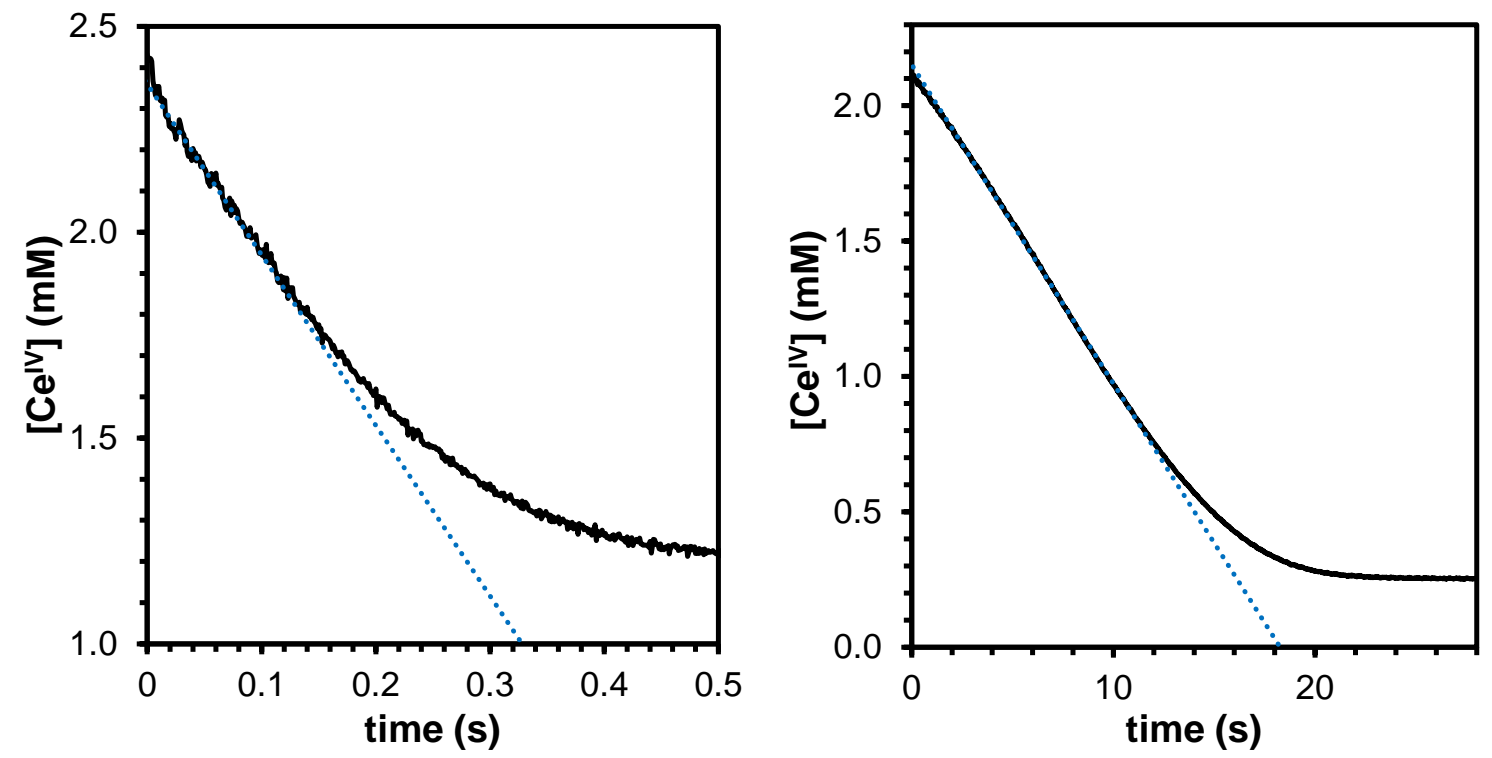

Figure 3. Plots of $\left[\mathrm{Ce}^{\mathrm{IV}}\right]$ vs time for $\left[\left(4,4^{\prime}-\mathrm{CF}_{3} \text {-bda)Ru(pic) }\right)_{2}\right]$ at $150 \mu \mathrm{M}$ (left) and $12.5 \mu \mathrm{M}$ (right). The slope of the dotted line represents the initial rate $d\left[\mathrm{Ce}^{\mathrm{IV}}\right] / d t$. 

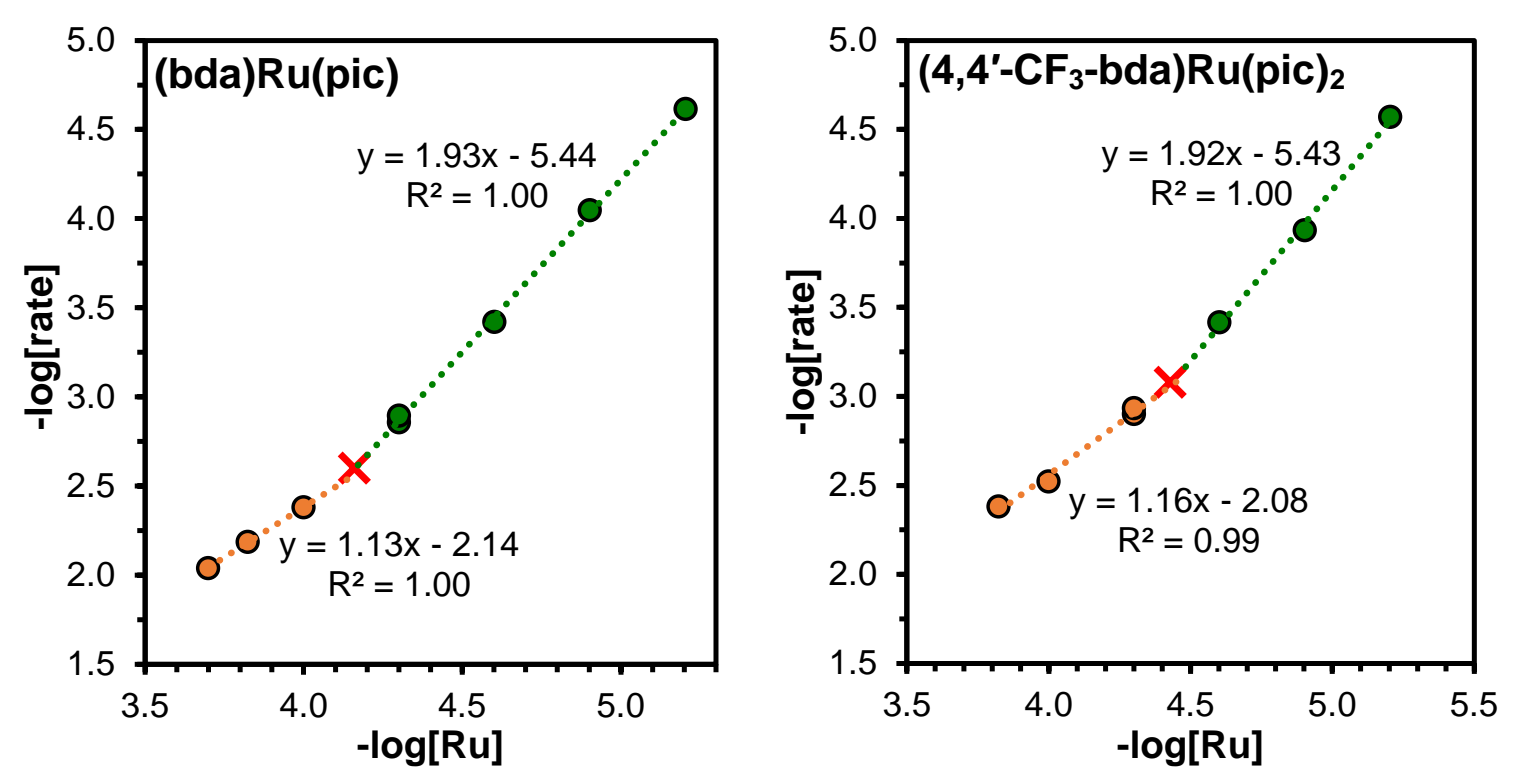

Figure 4. Plots of $-\log$ of the initial reaction rate vs $-\log [\mathrm{Ru}](\log / \log$ plots) for [(bda)Ru(pic) 2 ] (left) and $\left[\left(4,4^{\prime}-\mathrm{CF}_{3}-\mathrm{bda}\right) \mathrm{Ru}(\mathrm{pic})_{2}\right]$ (right), showing the concentration-dependent rate law regimes when $\left[\mathrm{Ce}^{\mathrm{IV}}\right]_{0}=2.0 \mathrm{mM}$. The red "X" represents the crossover concentration at which the rates of the two steps are equal, obtained from the calculated rate constants $k_{1,1}$ and $k_{2,0}$ defined in equations 1 and 2.

$$
\begin{aligned}
& \text { rate }=\frac{-d\left[C e^{I V}\right]}{d t}=k_{1,1}[R u]\left[C e^{I V}\right] \\
& \text { rate }=\frac{-d\left[C e^{I V}\right]}{d t}=k_{2,0}[R u]^{2} \\
& {[R u]_{X}=\left[C e^{I V}\right] \frac{k_{1,1}}{k_{2,0}}}
\end{aligned}
$$

Knowing the applicable rate laws for all concentrations, the two rate constants $k_{1,1}$ and $k_{2,0}$ were calculated for each of the six catalysts and are shown in Table 3. Using the log/log plots like those shown in Figure 4, the kinetic data for each catalyst was separated into oxidationlimited (slope $=1$, eq 1 ) and coupling-limited (slope $=2$, eq 2) regimes (see Figure S10 in the Supporting Information). For the oxidation-limited regime, observed rate constants $\left(k_{\mathrm{obs}}=\right.$ 
$\left.k_{1,1}[\mathrm{Ru}]\right)$ were determined from the slope of plots of $\ln \left[\mathrm{Ce}^{\mathrm{IV}}\right]$ vs time. For the coupling-limited regime, observed rate constants $\left(k_{\mathrm{obs}}=k_{2,0}[\mathrm{Ru}]^{2}\right)$ were determined from plots of $\left[\mathrm{Ce}^{\mathrm{IV}}\right]$ vs time. The observed rate constants and catalyst concentrations were then used to determine the rate constants for the oxidation step ( $k_{1,1}$, eq 1 , Figure S11) and the bimolecular coupling step ( $k_{2,0}$, eq 2, Figure S12), which are listed in Table 3. Values for $[\mathrm{Ru}]_{\mathrm{X}}$ were obtained from these rate constants and are listed in Table 3.

Table 3. Calculated rate constants for the oxidation step ( $k_{1,1}$, eq 1$)$ and bimolecular step ( $k_{2,0}$, eq 2) and crossover concentrations $[\mathrm{Ru}]_{\mathrm{X}}$ at which the rates of the two steps are equal when $[\mathrm{Ce}]=$ $2.0 \mathrm{mM}, 10 \% \mathrm{CH}_{3} \mathrm{CN}$ in $\mathrm{pH} 1 \mathrm{HClO}_{4}$.

\begin{tabular}{|c|c|c|c|}
\hline Complex & $k_{1,1}\left(M^{-1} s^{-1}\right)$ & $k_{2,0}\left(M^{-1} s^{-1}\right)$ & {$[\mathbf{R u}]_{\mathrm{X}}(\boldsymbol{\mu M})$} \\
\hline [(bda)Ru(pic) $\left.{ }_{2}\right]$ & $1.83(4) \times 10^{4}$ & $5.26(8) \times 10^{5}$ & $69(2)$ \\
\hline$\left[\left(4-\mathrm{CF}_{3}\right.\right.$-bda $\left.) \mathrm{Ru}(\mathrm{pic})_{2}\right]$ & $1.61(6) \times 10^{4}$ & $6.88(19) \times 10^{5}$ & $47(2)$ \\
\hline$\left[\left(4,4^{\prime}-\mathrm{CF}_{3}\right.\right.$-bda $\left.) \mathrm{Ru}(\mathrm{pic})_{2}\right]$ & $1.12(3) \times 10^{4}$ & $5.99(9) \times 10^{5}$ & $37(1)$ \\
\hline [(bda)Ru(isq) ${ }_{2}$ ] & $8.39(13) \times 10^{4}$ & $1.83(6) \times 10^{7}$ & $9.2(3)$ \\
\hline$\left[\left(4-\mathrm{CF}_{3}\right.\right.$-bda) $\left.\mathrm{Ru}(\mathrm{isq})_{2}\right]$ & $6.93(18) \times 10^{4}$ & $2.41(3) \times 10^{7}$ & $5.8(2)$ \\
\hline$\left[\left(4,4^{\prime}-\mathrm{CF}_{3}\right.\right.$-bda $\left.) \mathrm{Ru}(\mathrm{isq})_{2}\right]$ & $4.82(7) \times 10^{4}$ & $3.17(13) \times 10^{7}$ & $3.1(1)$ \\
\hline$\left[(\mathrm{bda}) \mathrm{Ru}(\mathrm{pic})_{2}\right]\left(\mathrm{D}_{2} \mathrm{O}\right)$ & $1.68(1) \times 10^{4}$ & $6.52(12) \times 10^{5}$ & $52(1)$ \\
\hline [(bda)Ru(isq) $\left.)_{2}\right]\left(\mathrm{D}_{2} \mathrm{O}\right)$ & $5.29(10) \times 10^{4}$ & $\sim 2.61(9) \times 10^{7 \dagger}$ & $\sim 4.1(2)^{\dagger}$ \\
\hline
\end{tabular}

${ }^{\dagger}$ Approximate values due to limited data in the second order regime. See text and ref 58.

The rate constants presented in Table 3 reveal the impact of the electron density of the R-bda ${ }^{2-}$ ligand and the nature of the axial ligand on the rates of both the oxidation and bimolecular steps. For each axial ligand, the rate constants for the oxidation step $\left(k_{1,1}\right)$ across the series of $\mathrm{bda}^{2-}, 4-$ $\mathrm{CF}_{3}-\mathrm{bda}^{2-}$, and 4,4'-CF $3-\mathrm{bda}^{2-}$ track as expected based on their oxidation potentials. Notably, it appears that the nature of the axial ligand has an even greater effect on the rate constant, with the 
isoquinoline ligand facilitating electron transfer to cerium(IV) relative to 4-picoline, despite the complexes' similar oxidation potentials. The trends in the rate constants for the bimolecular step $\left(k_{2,0}\right)$ are less straightforward. Clearly, the isoquinoline ligand greatly accelerates this step, with the rate constants being almost two orders of magnitude greater than the corresponding picoline derivatives. This is consistent with literature reports that [(bda)Ru(isq) 2 ] is a faster catalyst than [(bda)Ru(pic) $)_{2}$, presumably due to $\pi$-stacking interactions; ${ }^{28}$ however, this particular effect is irrelevant at concentrations above $\sim 10-{ }^{5} \mathrm{M}$, where the oxidation step is rate limiting. Among the three isoquinoline complexes, the rate constant for the bimolecular step tracks inversely with the electron density at the metal center. Consistent with this, $\left[\left(4,4^{\prime}-\mathrm{CF}_{3}-\mathrm{bda}\right) \mathrm{Ru}(\mathrm{pic})_{2}\right]$ exhibits a higher bimolecular rate constant than $\left[(\mathrm{bda}) \mathrm{Ru}(\mathrm{pic})_{2}\right]$, although $\left[\left(4-\mathrm{CF}_{3}-\mathrm{bda}\right) \mathrm{Ru}(\mathrm{pic})_{2}\right]$ is faster than both. A possible explanation is that the increased polarity of the nonsymmetric complex facilitates the bimolecular step in the picoline derivatives, but is overshadowed in the isoquinoline complexes presumably due to the $\pi$-stacking interactions.

To determine whether one or both of the rate-determining steps is proton-coupled, stoppedflow measurements were also carried out in $\mathrm{D}_{2} \mathrm{O}$ for [(bda)Ru(pic) $)_{2}$ ] and [(bda)Ru(isq) $)_{2}$. A solution of $4.0 \mathrm{mM}$ ceric ammonium nitrate in $0.20 \mathrm{M} \mathrm{DClO}_{4}$ was mixed with catalyst solutions of varying concentrations in $4: 1 \mathrm{D}_{2} \mathrm{O} / \mathrm{CH}_{3} \mathrm{CN}$ and kinetic constants, shown in Table 3, were extracted as described above. The kinetic isotope effects $\left(\mathrm{KIE}=k_{\mathrm{H}} / k_{\mathrm{D}}\right)$ for $k_{1,1}$ for the picoline and isoquinoline complexes are 1.1 and 1.6, respectively, indicating that there is proton loss associated with the rate-determining oxidation step. Consistent with the slower oxidation reaction, the crossover concentration between the two regimes was lowered from 69(2) to 52(1) $\mu \mathrm{M}$ for [(bda)Ru(pic) $)_{2}$ and from 9.2(3) to approximately $4.1(2) \mu \mathrm{M}$ for [(bda)Ru(isq) $)_{2}$. The calculated value of $k_{2,0}$ for [(bda)Ru(pic) $)_{2}$ is $6.52(12) \times 10^{5} \mathrm{M}^{-1} \mathrm{~s}^{-1}$, corresponding to an inverse 
$\mathrm{KIE}$ of 0.81 . In the case of $\left[(\mathrm{bda}) \mathrm{Ru}(\mathrm{isq})_{2}\right]$ the crossover concentration was much lower, preventing the collection of sufficient data points to reach a slope of 2 in the $\log / \log$ plot $^{60}$ The slope of the linear fit for the three points on the $\log / \log$ plot between $1.56 \mu \mathrm{M}$ and $0.39 \mu \mathrm{M}$ is 1.69. From these points, an approximate value of $2.6 \times 10^{7} \mathrm{M}^{-1} \mathrm{~s}^{-1}$ was obtained for $k_{2,0}$, corresponding to an inverse KIE of $\sim 0.7$ for the bimolecular step, comparable to the picoline complex. The inverse kinetic isotope effect observed for both bimolecular rate constants suggests the involvement of either an equilibrium preceding the bimolecular step or a secondary kinetic isotope effect related to hydrogen bonding or the slight differences in dielectric constants.

\section{Discussion}

The comparison of $\left[(\mathrm{R}-\mathrm{bda}) \mathrm{Ru}(\mathrm{L})_{2}\right]$ complexes with different bda substituents and axial ligands allows independent analysis of the effect of electron-density at the metal center and potential intermolecular effects from the axial ligand. Because different rate-determining steps were observed over the wide range of concentrations, we can make conclusions about both the electron-withdrawing nature of the R-bda ${ }^{2-}$ ligand and the secondary effect of the axial ligand in regards to both the rate-limiting oxidation step and the bimolecular step.

Two trends are apparent in the rate constant for the oxidation step, $k_{1,1}$, measured for cerium(IV)-driven catalysis. Of course, there is an inverse relationship between $k_{1,1}$ and the oxidation potential, resulting in a faster oxidation for the parent $b^{2-}{ }^{2-}$ complexes, although the differences across the series are smaller than might be expected. This is related to the diminished influence of the $-\mathrm{CF}_{3}$ groups on the $\mathrm{Ru}^{\mathrm{IV} / I I I}$ couple vs the $\mathrm{Ru}^{\mathrm{IIIIII}}$ couple, which is consistent with less contribution from the R-bda ${ }^{2-}$ ligand in the HOMO of the more highly oxidized complexes. As such, the differences in $\mathrm{Ru}^{\mathrm{V} / \mathrm{IV}}$ couples are likely to be smaller still (the presence of the catalytic wave precludes accurate electrochemical determination of the $\mathrm{Ru}^{\mathrm{V} / \mathrm{IV}}$ couples). The 
observed H/D KIE indicates that the rate-limiting oxidation is proton-coupled, either $\mathrm{Ru}^{\mathrm{III}}-\mathrm{OH}_{2}$ to $\mathrm{Ru}^{\mathrm{IV}}-\mathrm{OH}$ or $\mathrm{Ru}^{\mathrm{IV}}-\mathrm{OH}$ to $\mathrm{Ru}^{\mathrm{V}}=\mathrm{O}$.

In regard to the axial ligand, the rate of oxidation for the isoquinoline complexes is faster than the corresponding picoline complexes, demonstrating that the axial ligand can play an important role not only in secondary interactions between catalyst molecules, but also in facilitating electron transfer from the metal center. It is notable that the kinetic advantage afforded by the change in axial ligand has a greater impact on the rate constant than the thermodynamic differences caused by the installation of trifluoromethyl groups. In the concentration regime where the rate is limited by an oxidation step, [(bda)Ru(isq) $)_{2}$ is the fastest of the six catalysts studied here for cerium(IV)-driven water oxidation.

The rate of the bimolecular step, $k_{2,0}$, is also affected more by the nature of the axial ligand than the substituent on the R-bda ${ }^{2-}$ backbone. Consistent with previous reports, ${ }^{28}$ the outstanding trend in $k_{2,0}$ is the $30-50$ fold increase in the isoquinoline complexes relative to the corresponding picoline complexes for each variation of $\mathrm{R}-\mathrm{bda}^{2-}$. Among the three isoquinoline complexes studied here, a decrease in electron density appears to increase the rate of the bimolecular step, with $\left[\left(4,4^{\prime}-\mathrm{CF}_{3}-\mathrm{bda}\right) \mathrm{Ru}(\mathrm{isq})_{2}\right]$ being the fastest. Curiously, this trend does not hold for the picoline complexes, possibly due to an increased importance of the added dimension of polarity in 4-CF $3-\mathrm{bda}^{2-}$ in the slower bimolecular step of these complexes.

The inverse kinetic isotope effect observed for $k_{2,0}$ indicates that hydrogen bonding and/or a pre-equilibrium play a key role in the bimolecular step. Of the three mechanisms in Scheme 3, only pathways A or C include a bimolecular step; Pathway B does not include a step that is second-order in catalyst. Because it does not include any proton transfer, Pathway A would not exhibit a primary KIE for the bimolecular coupling step, however such behavior can be 
rationalized in a number of ways. An equilibrium that precedes the RDS could lead to the inverse KIE if it is affected by the stronger hydrogen bonding in $\mathrm{D}_{2} \mathrm{O}$ or involves a protonation step that is favored in $\mathrm{D}_{2} \mathrm{O}$. The small differences in static and dynamic dielectric constants between $\mathrm{H}_{2} \mathrm{O}$ and $\mathrm{D}_{2} \mathrm{O}$ are typically insignificant, but the drastic change in dipole between a highly polar $\mathrm{Ru}=\mathrm{O}$ monomer and a much less polar Ru-O-O-Ru dimer, could contribute to the small observed inverse KIE. The simplest explanation is that hydrogen bonding plays an important role in the bimolecular step and the barrier is therefore reduced by the stronger hydrogen bonding in $\mathrm{D}_{2} \mathrm{O}$. The intricate hydrogen bonding observed in the crystal structure of the ruthenium(IV) complex $\left(\mu-\mathrm{H}_{3} \mathrm{O}_{2}\right)\left[(\text { bda }) \mathrm{Ru}^{\mathrm{IV}}(\text { pic })_{2}\right]_{2}\left(\mathrm{H}_{2} \mathrm{O}\right)_{2}\left(\mathrm{PF}_{6}\right)_{3}\left(\mathrm{CH}_{3} \mathrm{CN}\right)$ would support such an explanation. ${ }^{27}$ The reaction of two $\mathrm{Ru}^{\mathrm{IV}}-\mathrm{OH}$ molecules to form a $\mu$-oxo dimer in pathway $\mathrm{C}$ requires the loss of a proton, which might be expected to exhibit a KIE greater than 1 . However, if the proton loss occurs in an equilibrium step preceding a slow dimerization, an inverse KIE could result. Thus, the bimolecular dependence under these conditions clearly rules out a single-site WNA pathway (Pathway B in Scheme 3), but the exact nature of the bimolecular step cannot be explicitly determined from our data (Pathway A vs Pathway C in Scheme 3). In the case of Pathway C, $k_{1,1}$ would apply to the $\mathrm{Ru}^{\mathrm{III}}-\mathrm{OH}_{2}$ to $\mathrm{Ru}^{\mathrm{IV}}-\mathrm{OH}$ oxidation, and $k_{2,0}$ would apply to the coupling of two $\mathrm{Ru}^{\mathrm{IV}}-\mathrm{OH}$ molecules. This would be consistent with our previously reported spectroelectrochemical and computational data, ${ }^{33}$ though the spectral data was recorded for surface-bound molecules, which may behave differently than those in solution. In the case of Pathway A, proposed by Sun and coworkers, ${ }^{61}$ our calculated values of $k_{1,1}$ would apply to the oxidation of $\mathrm{Ru}^{\mathrm{III}}-\mathrm{OH}_{2}$ or $\mathrm{Ru}^{\mathrm{IV}}-\mathrm{OH}$ and $k_{2,0}$ would apply to the coupling of two $\mathrm{Ru}^{\mathrm{V}}=\mathrm{O}$ molecules. 
The two kinetic regimes observed here could potentially account for discrepancies in the literature where some reports indicate second order behavior with respect to catalyst and others propose a different mechanism due to an observed first-order dependence on catalyst in electrochemical experiments. $^{28,}{ }^{30}$ However, it does remain possible that electrochemical catalysis proceeds through a different mechanism than cerium(IV)-driven catalysis. The difference between chemical and electrochemical studies is particularly important for surfacebound molecules, since any catalyst-catalyst bimolecular pathways would be severely inhibited, at least at planar electrodes. ${ }^{33,} 34$ A WNA mechanism was suggested for these catalysts under electrocatalytic conditions. ${ }^{30}$ However, in this mechanism one would expect little influence from the axial ligand and faster catalysis for the more electrophilic trifluoromethyl-substituted catalysts across all pH values when nucleophilic attack is rate-limiting, which is not the case in our experiments.

The electrocatalytic behavior for $\left[(\mathrm{R}-\mathrm{bda}) \mathrm{Ru}(\mathrm{L})_{2}\right]$ certainly does not obey the same trends observed in the cerium(IV)-driven experiments. At $1.0 \mathrm{mM}$ catalyst concentration the oxidation step is expected to be rate limiting based on the stopped-flow kinetic data, but $\left[\left(4,4^{\prime}-\mathrm{CF}_{3}\right.\right.$ bda)Ru(pic) $)_{2}$ ] produces a much greater catalytic current than the more easily-oxidized [(bda)Ru(pic) 2 ] at acidic $\mathrm{pH}$. A likely explanation is a faster heterogeneous electron transfer between the glassy carbon electrode and the complexes with more hydrophobic groups. That the isoquinoline catalysts are all relatively fast and exhibit much smaller differences between them is consistent with this explanation (see Figure S3 in the Supporting Information). Furthermore, the catalytic waves for $\left[\left(4,4^{\prime}-\mathrm{CF}_{3}-\mathrm{bda}\right) \mathrm{Ru}(\mathrm{pic})_{2}\right]$ are similar to $\left[\left(4,4^{\prime}-\mathrm{CF}_{3}-\mathrm{bda}\right) \mathrm{Ru}(\mathrm{isq})_{2}\right]$ for the acidic $\mathrm{pH}$ values at which this trend holds. Generally, with increasing $\mathrm{pH}$, the onset potentials for catalysis decrease and catalytic currents increase, as expected based on thermodynamics and 
base-enhanced PCET (see Figures S5 and S7 in the Supporting Information). ${ }^{30}$ At neutral pH, the isoquinoline catalysts are still more effective than the picoline catalysts, but the R-bda ${ }^{2-}$ series now obey the trend expected based on oxidation potential, with the unsubstituted bda ${ }^{2-}$ catalysts being faster. Clearly, there is a complex interplay between oxidation potential and secondary effects on electron transfer rate.

The possibility remains that the true active species is generated by decoordination of one of the axial L-type ligands. This would reduce the steric barrier to form a $\mu$-oxo dimer, which has been proposed previously based on spectroelectrochemical experiments. ${ }^{33}$ Consistent with this route is the report that complexes with a single labile dimethylsulfoxide ligand [(bda)Ru(DMSO)(imidazole)] are faster than [(bda)Ru(imidazole) 2 ], though this behavior was previously ascribed to steric effects. ${ }^{59}$ Oxo-bridged trimers resulting from oxidation of [(bda)Ru(pic) 2 ] have recently been described and shown to be active WOCs, though with rates slower than the monomeric catalysts. ${ }^{62,63}$

\section{Conclusion}

Variations of the known [(bda)Ru(L) 2 ] WOC were prepared with one and two trifluoromethyl substituents in the 4-positions of the $\mathrm{bda}^{2-}$ ligand. Kinetic studies of cerium-driven water oxidation using stopped-flow kinetic measurements showed that the rate of catalytic water oxidation by $\left[(\mathrm{R}-\mathrm{bda}) \mathrm{Ru}(\mathrm{L})_{2}\right]$ is limited by a proton-coupled oxidation step at catalyst concentrations on the order of $10^{-4} \mathrm{M}$ and by a bimolecular step at catalyst concentrations around $10^{-6} \mathrm{M}$. The importance of the oxidation-limited regime is notable considering the effort that has been applied to design assemblies that facilitate the bimolecular coupling step. ${ }^{64-67}$ Indeed, recent electrochemical studies have demonstrated the importance of electron transfer mediation in these systems, ${ }^{31,32}$ and our electrocatalytic data support this notion. 
Our data is consistent with the kinetic behavior observed in the literature in both cerium-driven and electrochemical experiments and supports a mechanism involving a bimolecular coupling of two catalyst molecules, such as Pathways A and C in Scheme 3. It remains possible that the mechanism differs depending on the nature of the oxidant, especially considering that cerium can play a non-innocent role in water oxidation catalysis. ${ }^{68,69}$

Because the RDS varies with catalyst concentration, potential improvements must consider the experimental conditions relevant to potential applications. The ideal catalyst is particular to any given system. ${ }^{70}$ This is illustrated in the varying effects of the installation of trifluoromethyl groups in $\left[\left(4,4^{\prime}-\mathrm{CF}_{3}-\mathrm{bda}\right) \mathrm{Ru}(\mathrm{L})_{2}\right]$ under different conditions. In cerium-mediated catalysis at $\mathrm{pH}$ $1,\left[\left(4,4^{\prime}-\mathrm{CF}_{3}-\mathrm{bda}\right) \mathrm{Ru}(\mathrm{L})_{2}\right]$ is a faster catalyst in dilute solutions but a slower one at higher catalyst concentrations. In water oxidation electrocatalysis at glassy carbon electrodes, $\left[\left(4,4^{\prime}-\mathrm{CF}_{3}-\right.\right.$ bda) $\left.\mathrm{Ru}(\mathrm{L})_{2}\right]$ is again faster at low $\mathrm{pH}$, but at neutral $\mathrm{pH}\left[(\mathrm{bda}) \mathrm{Ru}(\mathrm{L})_{2}\right]$ is the better catalyst. Of course, practical applications for this type of catalyst would require it to be driven photo- or electro-chemically. Thus, future work aims to apply conclusions from these basic studies towards integrated systems with photosensitizers and photoanodes.

\section{Experimental}

Synthetic Methods and Materials. The complexes described below are mildly air-sensitive. Reactions were carried out under argon using standard Schlenk techniques at ambient temperature $\left(21-24^{\circ} \mathrm{C}\right)$, unless otherwise noted. Workup and purification was performed in air. A nitrogen-filled glovebox was used for long term storage. Samples for analysis were prepared in air and used immediately. Oxidized impurities are easily separated from ruthenium(II) complexes by dissolving in $\mathrm{CH}_{2} \mathrm{Cl}_{2}$ and washing with aqueous ascorbic acid solution. Highpurity water was obtained by passing house-distilled water through a Millipore Milli-Q Synthesis 
A-10 system. 2-Methyl-6-(trimethylstannyl)pyridine ${ }^{51}$ and $\left[\mathrm{RuCl}_{2}\left(\mathrm{C}_{6} \mathrm{H}_{6}\right)\right]_{2}{ }^{71}$ were prepared according to the literature. All other reagents and solvents were purchased from commercial sources and used as received.

Physical Methods. Elemental analyses (EA) were performed by Robertson Microlit Laboratories. Electrospray ionization mass spectrometry (ESI-MS) was performed with a Thermo Finnigan LCQ Advantage LC/MS/MS. Nuclear magnetic resonance (NMR) spectra were recorded on a Bruker Avance III 400 spectrometer. ${ }^{1} \mathrm{H}$ NMR spectra were referenced to TMS using the residual protio impurities of the solvent, ${ }^{13} \mathrm{C}$ NMR spectra were referenced to TMS using the natural abundance ${ }^{13} \mathrm{C}$ of the solvent, and ${ }^{19} \mathrm{~F}$ NMR spectra were referenced to $\mathrm{CFCl}_{3}$ using the $\Xi$ scale with the corresponding ${ }^{1} \mathrm{H}$ spectra. ${ }^{72}$ All chemical shifts are reported in the standard $\delta$ notation in parts per million; positive chemical shifts are a higher frequency than the reference. Electronic absorption spectra were recorded with a UV-visible Agilent 8453 diode-array spectrophotometer and were corrected for the background spectrum of the solvent. Electrochemical measurements were performed with a $\mathrm{CH}$ Instruments $\mathrm{CH}-760 \mathrm{E}$ bipotentiostat at ambient temperature $\left(21-24^{\circ} \mathrm{C}\right)$ in a single compartment cell with a $3.0 \mathrm{~mm}$ glassy carbon disc working electrode, platinum wire counter electrode, and $\mathrm{Ag} / \mathrm{AgCl}$ (3 $\mathrm{M} \mathrm{NaCl}$ ) reference electrode. Solutions contained $1.0 \mathrm{mM}$ analyte with $10 \%$ acetonitrile in aqueous solution containing perchloric acid, nitric acid, phosphate buffer, or acetate buffer solutions. The reference electrode was calibrated to the ruthenium(III/II) couple of an internal $\left[\mathrm{Ru}(\mathrm{bpy})_{3}\right]\left(\mathrm{PF}_{6}\right)_{2}$ standard at 1.26 vs NHE. ${ }^{73}$ Stopped-flow kinetic measurements were performed at $25 \pm 0.1{ }^{\circ} \mathrm{C}$ with an Olis rapid scanning monochromator (Olis RSM-1000) equipped with an Olis USA stopped-flow. 
Synthesis of 2-iodo-6-methyl-4-trifluoromethylpyridine. This procedure was adapted from the synthesis of 2-iodo-pyrimidine. ${ }^{47}$ 2-chloro-6-methyl-4-trifluoromethylpyridine (5.0 g, 25.6 mmol) was added to $20 \mathrm{~mL}$ of hydriodic acid ( $57 \%$, precooled to $\left.0{ }^{\circ} \mathrm{C}\right)$. The mixture was allowed to warm up to room temperature under magnetic stirring. After 1 hour, $1 \mathrm{H}-\mathrm{NMR}$ showed no chloro-iodo conversion and the mixture was refluxed for 4 hours. At this point 1H-NMR showed $\sim 70 \%$ conversion of the chloropyridine to the corresponding iodopyridine. The mixture was allowed to cool to room temperature and then chilled in an ice bath. Saturated potassium carbonate solution was added until neutral $\mathrm{pH}$ was reached and the mixture was decolorized with potassium disulfite. The aqueous solution was extracted with diethyl ether (5 x $30 \mathrm{~mL})$ and the combined extracts were dried over anhydrous magnesium sulfate, filtered and the diethyl ether was removed by rotary evaporation. The yellow oil contained $~ 30 \%$ of the initial chloropyridine and was used in the next step without further purification. ${ }^{1} \mathrm{H}$ NMR $\left(\mathrm{CDCl}_{3}\right) \delta / \mathrm{ppm}: 7.72(\mathrm{~s}, 1 \mathrm{H}$, aryl-H), 7.30 (s, 1H, aryl-H), 2.59 (s, 3H, $\left.-\mathrm{CH}_{3}\right)$.

Synthesis of 6,6'-dimethyl-4,4'-bis(trifluoromethyl)-2,2'-bipyridine. This procedure was adapted from the synthesis of 4,4'-bis(trifluoromethyl)-2,2'-bipyridine. ${ }^{48}$ The 2-iodo-6-methyl-4trifluoromethylpyridine from the previous step was added into a Schlenk flask containing $15.0 \mathrm{~g}$ of activated copper bronze. ${ }^{47}$ The mixture was flushed with argon and heated at $170{ }^{\circ} \mathrm{C}$ for 8 hours. After cooling to room temperature the mixture was extracted several times with acetone and dichloromethane. The solvents were removed by rotary evaporation and the residue was dissolved in dichloromethane. Aqueous ammonia $(20 \mathrm{~mL})$ was added to the mixture and the organic fraction separated. This procedure was repeated two more times. The solution was dried with anhydrous magnesium sulfate, filtered and the solvent was removed by rotary evaporation. The sticky residue was dried at $70{ }^{\circ} \mathrm{C}$ under vacuum. The product ( $2.5 \mathrm{~g}, 61 \%$ from 2-chloro-6- 
methyl-4-trifluoromethylpyridine) was pure except for the presence of 2-chloro-6-methyl-4trifluoromethylpyridine from the previous step. The 2-iodo-6-methyl-4-trifluoromethylpyridine underwent quantitative coupling. ${ }^{1} \mathrm{H}$ NMR $\left(\mathrm{CDCl}_{3}\right) \delta / \mathrm{ppm}$ : $8.52(\mathrm{~s}, 2 \mathrm{H}$, aryl-H), $7.41(s, 2 \mathrm{H}$, aryl-H), $2.73\left(s, 6 \mathrm{H},-\mathrm{CH}_{3}\right)$. This material was used without further purification in the following step.

\section{Synthesis of 4,4'-bis(trifluoromethyl)-[2,2'-bipyridine]-6,6'-dicarboxylic acid $\left(4,4^{\prime}-\mathrm{CF}_{3^{-}}\right.$}

$\mathbf{b d a H}_{2}$ ). This procedure was adapted from the synthesis of 2,2'-bipyridine-6,6'-dicarboxylic acid. $^{49}$ 6,6'-dimethyl-4,4'-bis(trifluoromethyl)-2,2'-bipyridine (1.0 g, $3.12 \mathrm{mmol}, 1$ equiv) was added to a solution of sodium dichromate ( $2.28 \mathrm{~g}, 7.65 \mathrm{mmol}, 2.45$ equiv) in concentrated sulfuric acid $(10 \mathrm{~mL})$ under magnetic stirring. The mixture was heated at $80{ }^{\circ} \mathrm{C}$ for 1 hour, allowed to cool to $\sim 50{ }^{\circ} \mathrm{C}$ and then poured into $\sim 100 \mathrm{~g}$ of ice. The precipitate was collected by filtration and rinsed with water, a small amount of ethanol, and diethyl ether to yield a white solid (0.95 g, 80\%). ${ }^{1} \mathrm{H}$ NMR (DMSO-d ${ }_{6}$ ) $\delta /$ ppm: 9.01 (s, 2H, aryl-H), 8.40 (s, 2H, aryl-H).

Synthesis of $\quad 6,6^{\prime}$-dimethyl-4-trifluoromethyl-2,2'-bipyridine. 2-Methyl-6(trimethylstannyl)pyridine (1.212 g, 4.737 mmol, 1 equiv), 2-chloro-6-methyl-4(trifluoromethyl)pyridine (926 mg, $4.74 \mathrm{mmol}, 1$ equiv), and $\mathrm{Pd}\left(\mathrm{PPh}_{3}\right)_{4}(275 \mathrm{mg}, 238 \mu \mathrm{mol}, 0.05$ equiv) were combined in $30 \mathrm{~mL}$ anhydrous toluene under argon and refluxed for $21 \mathrm{~h}$. The solvent was removed and the residue was redissolved in $5 \mathrm{~mL} \mathrm{CH}_{2} \mathrm{Cl}_{2}$. The solution was then extracted with 3 x $30 \mathrm{~mL} 6 \mathrm{M} \mathrm{HCl}_{\text {(aq). }}$. The combined aqueous extracts were washed with $10 \mathrm{~mL}$ $\mathrm{Et}_{2} \mathrm{O}$, then cooled to $0{ }^{\circ} \mathrm{C}$ and neutralized with $\mathrm{NH}_{4} \mathrm{OH}$. The light orange solid was separated by filtration, washed with water, and dried in vacuo (804 mg, 67\%). ${ }^{1} \mathrm{H}$ NMR $\left(\mathrm{CDCl}_{3}\right) \delta / \mathrm{ppm}: 8.48$ (s, 1H, aryl-H), $8.23\left(d,{ }^{3} J_{\mathrm{HH}}=7.8 \mathrm{~Hz}, 1 \mathrm{H}\right.$, aryl-H), $7.71\left(d,{ }^{3} J_{\mathrm{HH}}=7.7 \mathrm{~Hz}, 1 \mathrm{H}\right.$, aryl-H), $7.36(s$,

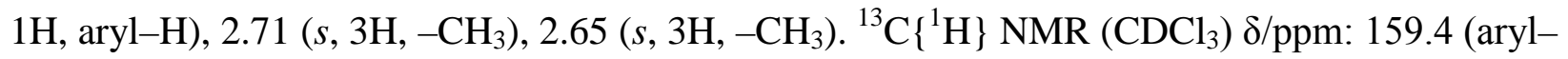


C), 158.3 (aryl-C), 157.5 (aryl-C), 154.6 (aryl-C), 139.5 ( $q,{ }^{2} J_{\mathrm{CF}}=34 \mathrm{~Hz}$, aryl-C), 137.3 (aryl-

C), 124.7 (aryl-C), $123.3\left(q,{ }^{1} J_{\mathrm{CF}}=273 \mathrm{~Hz},-\mathrm{CF}_{3}\right), 118.5\left(q,{ }^{3} J_{\mathrm{CF}}=4 \mathrm{~Hz}\right.$, aryl-C), 118.5 (aryl-

C), $114.2\left(q,{ }^{3} J_{\mathrm{CF}}=4 \mathrm{~Hz}\right.$, aryl-C), $24.9\left(-\mathrm{CH}_{3}\right), 24.8\left(-\mathrm{CH}_{3}\right) .{ }^{19} \mathrm{~F}\left\{{ }^{1} \mathrm{H}\right\} \mathrm{NMR}\left(\mathrm{CDCl}_{3}\right) \delta / \mathrm{ppm}$ : $64.68\left(-\mathrm{CF}_{3}\right)$.

\section{Synthesis of 4-trifluoromethyl-[2,2'-bipyridine]-6,6'-dicarboxylic acid $\left(4-\mathrm{CF}_{3}-\mathrm{bdaH}_{2}\right)$.}

Solid 6,6'-dimethyl-4-trifluoromethyl-2,2'-bipyridine (801 mg, $3.18 \mathrm{mmol}$, 1 equiv) was added to a solution of $\mathrm{Na}_{2} \mathrm{Cr}_{2} \mathrm{O}_{7} \cdot 2 \mathrm{H}_{2} \mathrm{O}$ (2.322 g, $7.792 \mathrm{mmol}$, 2.45 equiv) in $12 \mathrm{~mL}$ concentrated $\mathrm{H}_{2} \mathrm{SO}_{4}$. The dark orange solution was stirred at room temperature for $20 \mathrm{~min}$, becoming green-brown and warm. Heating at $80{ }^{\circ} \mathrm{C}$ for $1 \mathrm{~h}$ produced a dark green solution, which was then poured into ca. $90 \mathrm{~mL}$ crushed ice, producing a white solid. The mixture was filtered and the solid was washed with $3 \times 10 \mathrm{~mL} \mathrm{H}_{2} \mathrm{O}$ and $2 \times 5 \mathrm{~mL} \mathrm{Et}_{2} \mathrm{O}$ (838 mg, 84\%). ${ }^{1} \mathrm{H}$ NMR (DMSO- $\left.d_{6}\right) \delta / p p m: 13.78(b r$ s, 1H, $-\mathrm{COOH}), 13.43$ (br s, $1 \mathrm{H},-\mathrm{COOH}), 9.07$ (s, 1H, aryl-H), $8.76\left(d,{ }^{3} J_{\mathrm{HH}}=7.0 \mathrm{~Hz}, 1 \mathrm{H}\right.$, aryl-H), 8.34 (s, 1H, aryl-H), 8.26-8.21 (m, 2H, aryl-H). ${ }^{13} \mathrm{C}\left\{{ }^{1} \mathrm{H}\right\}$ NMR (DMSO-d $\left.{ }_{6}\right) \delta /$ ppm: 165.5 (-COOH), 164.8 (-COOH), 156.2 (aryl-C), 153.0 (aryl-C), 150.1 (aryl-C), 148.1 (arylC), 139.5 (aryl-C), 139.2 ( $q,{ }^{2} J_{\mathrm{CF}}=34 \mathrm{~Hz}$, aryl-C), 126.0 (aryl-C), 124.5 (aryl-C), 122.7 ( $q,{ }^{1} J_{\mathrm{CF}}$ $\left.=273 \mathrm{~Hz},-\mathrm{CF}_{3}\right), 120.4\left(q,{ }^{3} J_{\mathrm{CF}}=4 \mathrm{~Hz}\right.$, aryl-C), $119.4\left(q,{ }^{3} J_{\mathrm{CF}}=4 \mathrm{~Hz}\right.$, aryl-C). ${ }^{19} \mathrm{~F}\left\{{ }^{1} \mathrm{H}\right\} \mathrm{NMR}$ (DMSO-d $\left.)_{6}\right) \delta /$ ppm: $63.31\left(-\mathrm{CF}_{3}\right)$.

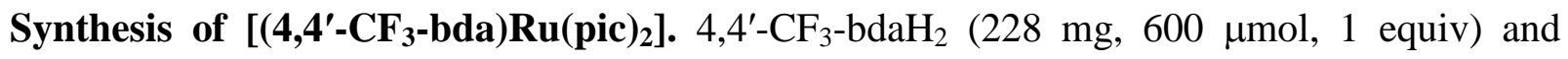
$\left[\mathrm{RuCl}_{2}\left(\mathrm{C}_{6} \mathrm{H}_{6}\right)\right]_{2}\left(150 \mathrm{mg}, 300 \mu \mathrm{mol}, 0.5\right.$ equiv) were combined in $30 \mathrm{~mL} \mathrm{CH}_{3} \mathrm{OH}$. The suspension was degassed by bubbling with argon, then refluxed for $2 \mathrm{~h}$, producing a dark purple solution. The reaction mixture was removed from heat, treated with triethylamine $(1.0 \mathrm{~mL}$, excess) and 4-picoline (0.5 mL, excess), and refluxed for an additional $15 \mathrm{~h}$. The reaction mixture was filtered after cooling to room temperature and then evaporated, providing a 
burgundy residue. The latter was dissolved in $\mathrm{CHCl}_{3}$ and washed three times with an aqueous solution of ascorbic acid. The $\mathrm{CHCl}_{3}$ solution was dried with anhydrous magnesium sulfate, filtered and taken to dryness by rotary evaporation. The crude product was purified by column chromatography on silica gel with 4:1 $\mathrm{CH}_{2} \mathrm{Cl}_{2} / \mathrm{CH}_{3} \mathrm{OH}$. The fractions containing pure product by UV-vis absorption were combined and evaporated (208 mg, 52\%). Anal. Calcd. (Found) for $\mathrm{C}_{26} \mathrm{H}_{18} \mathrm{~F}_{6} \mathrm{~N}_{4} \mathrm{O}_{4} \mathrm{Ru}$ (\%): C, $46.92 \quad$ (46.66); $\mathrm{H}, \quad 2.73 \quad$ (2.68); $\quad \mathrm{N}, \quad 8.42 \quad$ (8.64). ESI-MS (acetone/methanol) m/z: $667.0\left([\mathrm{M}+\mathrm{H}]^{+}\right), 688.9\left([\mathrm{M}+\mathrm{Na}]^{+}\right), 704.8\left([\mathrm{M}+\mathrm{K}]^{+}\right) .{ }^{1} \mathrm{H}$ NMR $\left(\mathrm{CD}_{2} \mathrm{Cl}_{2}\right)$

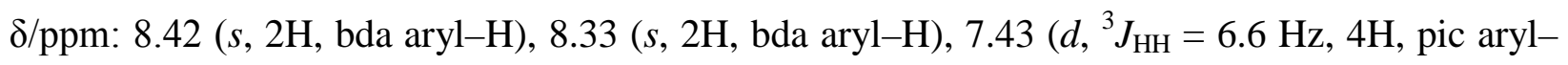
$\mathrm{H}), 6.91\left(d,{ }^{3} \mathrm{~J}_{\mathrm{HH}}=6.0 \mathrm{~Hz}, 4 \mathrm{H}\right.$, pic aryl-H), $2.23\left(\mathrm{~s}, 6 \mathrm{H}\right.$, pic $\left.-\mathrm{CH}_{3}\right) .{ }^{13} \mathrm{C}\left\{{ }^{1} \mathrm{H}\right\} \mathrm{NMR}\left(\mathrm{CD}_{2} \mathrm{Cl}_{2}\right)$ ઈ/ppm: 171.8 (bda aryl-COO-), 160.6 (bda aryl-C), 159.8 (bda aryl-C), 150.8 (pic aryl-C), 150.0 (pic aryl-C), 131.3 ( $q,{ }^{2} J_{\mathrm{CF}}=35 \mathrm{~Hz}$, bda aryl-C), 126.5 (pic aryl-C), 123.5 ( $q,{ }^{1} J_{\mathrm{CF}}=273$ $\mathrm{Hz}$, bda $-\mathrm{CF}_{3}$ ), 122.6 ( $q,{ }^{3} J_{\mathrm{CF}}=4 \mathrm{~Hz}$, bda aryl-C), 120.0 ( $q$, ${ }^{3} J_{\mathrm{CF}}=4 \mathrm{~Hz}$, bda aryl-C), 21.0 (pic $\left.\mathrm{CH}_{3}\right) .{ }^{19} \mathrm{~F}\left\{{ }^{1} \mathrm{H}\right\}$ NMR $\left(\mathrm{CD}_{2} \mathrm{Cl}_{2}\right) \delta /$ ppm: $64.04\left(-\mathrm{CF}_{3}\right) . \mathrm{UV}$-vis $\left(\mathrm{CH}_{2} \mathrm{Cl}_{2}\right) \lambda_{\max } / \mathrm{nm}\left(\epsilon / \mathrm{M}^{-1} \mathrm{~cm}^{-1}\right): 306$ (22000), 340 (8700), 356 (8700), 424 (10000).

Synthesis of $\left[\left(\mathbf{4}^{\prime} \mathbf{4}^{\prime}-\mathbf{C F}_{3}-\mathbf{b d a}\right) \mathbf{R u}(\mathbf{i s q})_{2}\right] \cdot{ }^{4} 4^{\prime}-\mathrm{CF}_{3}-\mathrm{bdaH}_{2}(228 \mathrm{mg}, 600 \mu \mathrm{mol}, 1$ equiv) and $\left[\mathrm{RuCl}_{2}\left(\mathrm{C}_{6} \mathrm{H}_{6}\right)\right]_{2}\left(150 \mathrm{mg}, 300 \mu \mathrm{mol}, 0.5\right.$ equiv) were combined in $30 \mathrm{~mL} \mathrm{CH} \mathrm{CH}_{3} \mathrm{OH}$. The suspension was degassed by bubbling with argon, then refluxed for $2 \mathrm{~h}$, producing a dark purple solution. The reaction mixture was removed from heat, treated with triethylamine $(1.0 \mathrm{~mL}$, excess) and isoquinoline (0.6 mL, excess), and refluxed for an additional $15 \mathrm{~h}$. The reaction mixture was filtered after cooling to room temperature and then evaporated, providing a burgundy residue. The latter was dissolved in $\mathrm{CHCl}_{3}$ and washed three times with an aqueous solution of ascorbic acid. The $\mathrm{CHCl}_{3}$ solution was dried with anhydrous magnesium sulfate, filtered and taken to dryness by rotary evaporation. The crude product was purified by column 
chromatography on silica gel with 4:1 $\mathrm{CH}_{2} \mathrm{Cl}_{2} / \mathrm{CH}_{3} \mathrm{OH}$. The fractions containing pure product by UV-vis absorption were combined and evaporated (199 mg, 45\%). Anal. Calcd. (Found) for $\mathrm{C}_{32} \mathrm{H}_{18} \mathrm{~F}_{6} \mathrm{~N}_{4} \mathrm{O}_{4} \mathrm{Ru} \quad$ (\%): $\quad \mathrm{C}, \quad 52.11 \quad$ (51.92); $\quad \mathrm{H}, \quad 2.46 \quad$ (2.68); $\quad \mathrm{N}, \quad 7.60 \quad$ (7.53). $\quad$ ESI-MS (acetone/methanol) m/z: $739.0\left([\mathrm{M}+\mathrm{H}]^{+}\right), 761.0\left([\mathrm{M}+\mathrm{Na}]^{+}\right), 776.9\left([\mathrm{M}+\mathrm{K}]^{+}\right) .{ }^{1} \mathrm{H}$ NMR $\left(\mathrm{CD}_{2} \mathrm{Cl}_{2}\right)$ f/ppm: 8.56 (s, 2H, bda aryl-H), 8.52 (s, 2H, isq aryl-H), 8.33 (s, 2H, bda aryl-H), $7.84\left(d,{ }^{3} J_{\mathrm{HH}}\right.$ $=8.3 \mathrm{~Hz}, 2 \mathrm{H}$, isq aryl-H), $7.76\left(d,{ }^{3} J_{\mathrm{HH}}=8.2 \mathrm{~Hz}, 2 \mathrm{H}\right.$, isq aryl-H), $7.72\left(t d,{ }^{3} J_{\mathrm{HH}}=7.5 \mathrm{~Hz},{ }^{4} J_{\mathrm{HH}}=\right.$ $1.1 \mathrm{~Hz}, 2 \mathrm{H}$, isq aryl-H), $7.62\left(d d d,{ }^{3} J_{\mathrm{HH}}=8.1 \mathrm{~Hz},{ }^{3} J_{\mathrm{HH}}=6.6 \mathrm{~Hz},{ }^{4} J_{\mathrm{HH}}=1.1 \mathrm{~Hz}, 2 \mathrm{H}\right.$, isq aryl-H), $7.46\left(d,{ }^{3} J_{\mathrm{HH}}=6.6 \mathrm{~Hz}, 2 \mathrm{H}\right.$, isq aryl-H), $7.33\left(d,{ }^{3} J_{\mathrm{HH}}=6.5 \mathrm{~Hz}, 2 \mathrm{H}\right.$, isq aryl-H). ${ }^{13} \mathrm{C}\left\{{ }^{1} \mathrm{H}\right\}$ NMR

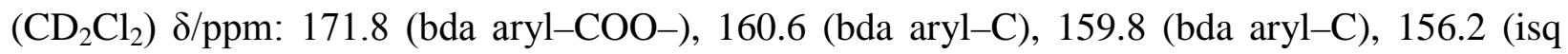
aryl-C), 142.1 (isq aryl-C), 135.5 (isq aryl-C), 132.8 (isq aryl-C), $131.7\left(q,{ }^{2} J_{\mathrm{CF}}=35 \mathrm{~Hz}\right.$, bda aryl-C), 129.1 (isq aryl-C), 129.0 (isq aryl-C), 128.0 (isq aryl-C), 126.7 (isq aryl-C), 123.5 (q, ${ }^{1} J_{\mathrm{CF}}=273 \mathrm{~Hz}$, bda $\left.-\mathrm{CF}_{3}\right), 122.7\left(q,{ }^{3} J_{\mathrm{CF}}=4 \mathrm{~Hz}\right.$, bda aryl-C), 122.7 (isq aryl-C), $120.3\left(q,{ }^{3} J_{\mathrm{CF}}=\right.$ $4 \mathrm{~Hz}$, bda aryl-C). ${ }^{19} \mathrm{~F}\left\{{ }^{1} \mathrm{H}\right\}$ NMR $\left(\mathrm{CD}_{2} \mathrm{Cl}_{2}\right) \delta / \mathrm{ppm}$ : $64.00\left(-\mathrm{CF}_{3}\right)$. UV-vis $\left(\mathrm{CH}_{2} \mathrm{Cl}_{2}\right) \lambda_{\max } / \mathrm{nm}$ ( $\left./ \mathrm{M}^{-1} \mathrm{~cm}^{-1}\right): 256$ (25000), 305 (28000), 409 (16000).

Synthesis of $\left[\left(4-\mathbf{C F}_{3}-\mathbf{b d a}\right) \mathbf{R u}(\mathbf{p i c})_{2}\right] .4-\mathrm{CF}_{3}-\mathrm{bdaH}_{2}(402 \mathrm{mg}, 1.28 \mathrm{mmol}, 1$ equiv) and $\left[\mathrm{RuCl}_{2}\left(\mathrm{C}_{6} \mathrm{H}_{6}\right)\right]_{2}\left(322 \mathrm{mg}, 644 \mu \mathrm{mol}, 0.5\right.$ equiv) were combined in $30 \mathrm{~mL} \mathrm{CH} \mathrm{CH}_{3} \mathrm{OH}$. The suspension was degassed by bubbling with argon, then refluxed for $2 \mathrm{~h}$, producing a dark purple solution. The reaction mixture was removed from heat, treated with triethylamine $(0.7 \mathrm{~mL}, 5$ mmol, 4 equiv) and 4-picoline (0.26 mL, 2.7 mmol, 2.1 equiv), and refluxed for an additional 15 h. The reaction mixture was then evaporated, providing a burgundy residue. The product was purified by column chromatography on silica gel with $4: 1 \mathrm{CH}_{2} \mathrm{Cl}_{2} / \mathrm{CH}_{3} \mathrm{OH}$. The fractions containing pure product by UV-vis absorption were combined and evaporated. The resulting residue was treated with $3 \times 30 \mathrm{~mL} 0.05 \mathrm{M}$ ascorbic acid, filtered, washed with $10 \mathrm{~mL} \mathrm{H}_{2} \mathrm{O}$ and 
$10 \mathrm{~mL} \mathrm{Et} t_{2} \mathrm{O}$, and dried in vacuo (479 mg, 62\%). Anal. Calcd. (Found) for $\mathrm{C}_{25} \mathrm{H}_{19} \mathrm{~F}_{3} \mathrm{~N}_{4} \mathrm{O}_{4} \mathrm{Ru}$ (\%): C, 50.25 (49.65); H, 3.21 (3.08); N, 9.38 (9.21). ESI-MS (acetone/methanol) m/z: 598.9 $\left([\mathrm{M}+\mathrm{H}]^{+}\right), 620.8\left([\mathrm{M}+\mathrm{Na}]^{+}\right), 678.7\left([\mathrm{M}+\mathrm{K}]^{+}\right) .{ }^{1} \mathrm{H}$ NMR $\left(\mathrm{CD}_{2} \mathrm{Cl}_{2}\right) \delta / \mathrm{ppm}: 8.30(\mathrm{~s}, 1 \mathrm{H}$, bda aryl$\mathrm{H}), 8.26\left(d,{ }^{3} J_{\mathrm{HH}}=8.1 \mathrm{~Hz}, 1 \mathrm{H}\right.$, bda aryl-H), $8.24\left(\mathrm{~s}, 1 \mathrm{H}\right.$, bda aryl-H), $8.11\left(d,{ }^{3} J_{\mathrm{HH}}=7.6 \mathrm{~Hz}, 1 \mathrm{H}\right.$, bda aryl-H), $7.76\left(t,{ }^{3} J_{\mathrm{HH}}=7.9 \mathrm{~Hz}, 1 \mathrm{H}\right.$, bda aryl-H), $7.51\left(d,{ }^{3} J_{\mathrm{HH}}=6.4 \mathrm{~Hz}, 4 \mathrm{H}\right.$, pic aryl-H), $6.90\left(d,{ }^{3} \mathrm{~J}_{\mathrm{HH}}=6.1 \mathrm{~Hz}, 4 \mathrm{H}\right.$, pic aryl-H), $2.22\left(\mathrm{~s}, 6 \mathrm{H}\right.$, pic $\left.-\mathrm{CH}_{3}\right) .{ }^{13} \mathrm{C}\left\{{ }^{1} \mathrm{H}\right\} \mathrm{NMR}\left(\mathrm{CD}_{2} \mathrm{Cl}_{2} / \mathrm{CD}_{3} \mathrm{OD}\right)$ ઈ/ppm: 173.4 (bda aryl-COO-), 172.7 (bda aryl-COO-), 161.6 (bda aryl-C), 159.3 (bda arylC), 159.3 (bda aryl-C), 157.6 (bda aryl-C), 151.1 (pic aryl-C), 149.8 (pic aryl-C), 132.0 (bda aryl-C), 130.9 ( $q,{ }^{2} J_{\mathrm{CF}}=35 \mathrm{~Hz}$, bda aryl-C), 126.7 (bda aryl-C), 126.4 (pic aryl-C), 124.7 (bda $\operatorname{aryl}-\mathrm{C}), 123.6\left(q,{ }^{1} J_{\mathrm{CF}}=273 \mathrm{~Hz}\right.$, bda $\left.-\mathrm{CF}_{3}\right), 122.3\left(q,{ }^{3} J_{\mathrm{CF}}=4 \mathrm{~Hz}\right.$, bda aryl-C), $120.0\left(q,{ }^{3} J_{\mathrm{CF}}=\right.$ $4 \mathrm{~Hz}$, bda aryl-C), 20.9 (pic $\left.-\mathrm{CH}_{3}\right) .{ }^{19} \mathrm{~F}\left\{{ }^{1} \mathrm{H}\right\}$ NMR $\left(\mathrm{CD}_{2} \mathrm{Cl}_{2}\right) \delta /$ ppm: $64.02\left(-\mathrm{CF}_{3}\right)$. UV-vis $\left(\mathrm{CH}_{2} \mathrm{Cl}_{2}\right) \lambda_{\max } / \mathrm{nm}\left(\epsilon / \mathrm{M}^{-1} \mathrm{~cm}^{-1}\right): 250$ (20000), 305 (24000), 370 (9600), 415 (8300), 489 (4500).

Synthesis of $\left[\left(4-\mathbf{C F}_{3} \text {-bda)Ru(isq) }\right)_{2}\right] .4-\mathrm{CF}_{3}-\mathrm{bdaH}_{2}(428 \mathrm{mg}, 1.37 \mathrm{mmol}, 1$ equiv) and $\left[\mathrm{RuCl}_{2}\left(\mathrm{C}_{6} \mathrm{H}_{6}\right)\right]_{2}\left(343 \mathrm{mg}, 685 \mu \mathrm{mol}, 0.5\right.$ equiv) were combined in $30 \mathrm{~mL} \mathrm{CH} \mathrm{CH}_{3} \mathrm{OH}$. The suspension was degassed by bubbling with argon, then refluxed for $2.5 \mathrm{~h}$, producing a dark purple solution. The reaction mixture was removed from heat, treated with triethylamine (0.76 $\mathrm{mL}, 5.5 \mathrm{mmol}$, 4 equiv) and isoquinoline $(0.35 \mathrm{~mL}, 3.0 \mathrm{mmol}, 2.2$ equiv), and refluxed for an additional $15 \mathrm{~h}$. The reaction mixture was then evaporated, providing a brown-red residue. The product was purified by column chromatography on silica gel with $4: 1 \mathrm{CH}_{2} \mathrm{Cl}_{2} / \mathrm{CH}_{3} \mathrm{OH}$. The fractions containing pure product by UV-vis absorption were combined and evaporated. The resulting residue was treated with 3 x $30 \mathrm{~mL} 0.05 \mathrm{M}$ ascorbic acid, filtered, washed with $10 \mathrm{~mL}$ $\mathrm{H}_{2} \mathrm{O}$ and $10 \mathrm{~mL} \mathrm{Et}{ }_{2} \mathrm{O}$, and dried in vacuo (657 mg, 72\%). Anal. Calcd. (Found) for

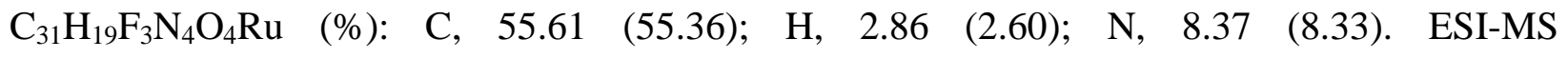


(acetone/methanol) m/z: $671.0\left([\mathrm{M}+\mathrm{H}]^{+}\right), 692.8\left([\mathrm{M}+\mathrm{Na}]^{+}\right), 708.8\left([\mathrm{M}+\mathrm{K}]^{+}\right) .{ }^{1} \mathrm{H}$ NMR $\left(\mathrm{CD}_{2} \mathrm{Cl}_{2}\right)$

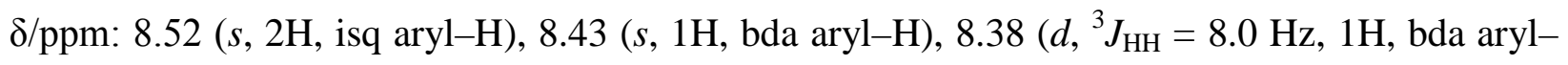
$\mathrm{H}), 8.24\left(\mathrm{~s}, 1 \mathrm{H}\right.$, bda aryl-H), $8.12\left(d,{ }^{3} J_{\mathrm{HH}}=7.6 \mathrm{~Hz}, 1 \mathrm{H}\right.$, bda aryl-H), $7.83\left(t,{ }^{3} J_{\mathrm{HH}}=7.9 \mathrm{~Hz}, 1 \mathrm{H}\right.$, bda aryl-H), $7.80\left(d,{ }^{3} J_{\mathrm{HH}}=7.9 \mathrm{~Hz}, 2 \mathrm{H}\right.$, isq aryl-H), $7.74\left(d,{ }^{3} J_{\mathrm{HH}}=8.1 \mathrm{~Hz}, 2 \mathrm{H}\right.$, isq aryl-H), $7.70\left(t,{ }^{3} J_{\mathrm{HH}}=7.4 \mathrm{~Hz}, 2 \mathrm{H}\right.$, isq aryl-H), $7.60\left(t,{ }^{3} J_{\mathrm{HH}}=7.4 \mathrm{~Hz}, 2 \mathrm{H}\right.$, isq aryl-H), $7.48\left(d,{ }^{3} J_{\mathrm{HH}}=\right.$ $6.5 \mathrm{~Hz}, 2 \mathrm{H}$, isq aryl-H), $7.44\left(d,{ }^{3} J_{\mathrm{HH}}=6.5 \mathrm{~Hz}, 2 \mathrm{H}\right.$, isq aryl-H). ${ }^{13} \mathrm{C}\left\{{ }^{1} \mathrm{H}\right\}$ NMR ( $\mathrm{CD}_{2} \mathrm{Cl}_{2} / \mathrm{CD}_{3} \mathrm{OD}$ ) $\delta /$ ppm: 173.5 (bda aryl-COO-), 172.8 (bda aryl-COO-), 161.6 (bda aryl-C), 159.3 (bda aryl-C), 159.2 (bda aryl-C), 157.5 (bda aryl-C), 156.3 (isq aryl-C), 142.6 (isq arylC), 135.4 (isq aryl-C), 132.7 (isq aryl-C), 132.4 (bda aryl-C), 131.4 ( $q,{ }^{2} J_{\mathrm{CF}}=35 \mathrm{~Hz}$, bda arylC), 129.0 (isq aryl-C), 129.0 (isq aryl-C), 127.8 (isq aryl-C), 126.8 (bda aryl-C), 126.7 (isq aryl-C), 125.2 (bda aryl-C), 123.5 ( $q$, ${ }^{1} J_{\mathrm{CF}}=273 \mathrm{~Hz}$, bda $-\mathrm{CF}_{3}$ ), 122.5 (isq aryl-C), 122.5 (br, bda aryl-C), 120.5 (br, bda aryl-C). ${ }^{19} \mathrm{~F}\left\{{ }^{1} \mathrm{H}\right\}$ NMR $\left(\mathrm{CD}_{2} \mathrm{Cl}_{2} / \mathrm{CD}_{3} \mathrm{OD}\right) \delta / \mathrm{ppm}$ : $64.16\left(-\mathrm{CF}_{3}\right)$. UVvis $\left(\mathrm{CH}_{2} \mathrm{Cl}_{2}\right) \lambda_{\max } / \mathrm{nm}\left(\epsilon / \mathrm{M}^{-1} \mathrm{~cm}^{-1}\right): 256$ (23000), 304 (31000), 419 (16000).

\section{ASSOCIATED CONTENT}

Supporting Information. NMR spectra for [(4-CF 3 -bda)Ru(pic $\left.)_{2}\right]$, electronic absorption spectra for new complexes, additional electrochemical and stopped-flow data, crystallographic details, and cif files. This material is available free of charge via the Internet at http://pubs.acs.org.

\section{AUTHOR INFORMATION}

\section{Corresponding Author}

* jconcepc@bnl.gov . 


\section{Notes}

The authors declare no competing financial interests.

\section{ACKNOWLEDGMENT}

This work was carried out at Brookhaven National Laboratory and it was supported by the U.S.

Department of Energy, Office of Science, Division of Chemical Sciences, Geosciences, \&

Biosciences, Office of Basic Energy Sciences under contract DE-SC00112704.

\section{REFERENCES}

1. Kärkäs, M. D.; Verho, O.; Johnston, E. V.; Åkermark, B. Artificial Photosynthesis: Molecular Systems for Catalytic Water Oxidation. Chem. Rev. 2014, 114, 11863-12001.

2. Sala, X.; Maji, S.; Bofill, R.; García-Antón, J.; Escriche, L.; Llobet, A. Molecular Water Oxidation Mechanisms Followed by Transition Metals: State of the Art. Acc. Chem. Res. 2014, 47, 504-516.

3. Clark, A. E.; Hurst, J. K. Mechanisms of Water Oxidation Catalyzed by Ruthenium Coordination Complexes. In Prog. Inorg. Chem., John Wiley \& Sons, Inc.: 2011; Vol. 57, pp 154.

4. Wasylenko, D. J.; Palmer, R. D.; Berlinguette, C. P. Homogeneous water oxidation catalysts containing a single metal site. Chem. Commun. 2013, 49, 218-227.

5. Cao, R.; Lai, W.; Du, P. Catalytic water oxidation at single metal sites. Energy Environ. Sci. 2012, 5, 8134-8157.

6. Casadevall, C.; Codolà, Z.; Costas, M.; Lloret-Fillol, J. Spectroscopic, Electrochemical and Computational Characterisation of Ru Species Involved in Catalytic Water Oxidation: Evidence for a [RuV(O)(Py2Metacn)] Intermediate. Chem. - Eur. J. 2016, 22, 10111-10126.

7. Fillol, J. L.; Codolà, Z.; Garcia-Bosch, I.; Gómez, L.; Pla, J. J.; Costas, M. Efficient water oxidation catalysts based on readily available iron coordination complexes. Nat. Chem. 2011, 3, 807-813.

8. Gersten, S. W.; Samuels, G. J.; Meyer, T. J. Catalytic oxidation of water by an oxobridged ruthenium dimer. J. Am. Chem. Soc. 1982, 104, 4029-4030.

9. $\quad$ Liu, F.; Concepcion, J. J.; Jurss, J. W.; Cardolaccia, T.; Templeton, J. L.; Meyer, T. J. Mechanisms of Water Oxidation from the Blue Dimer to Photosystem II. Inorg. Chem. 2008, 47, 1727-1752.

10. Bianco, R.; Hay, P. J.; Hynes, J. T. Theoretical Study of O-O Single Bond Formation in the Oxidation of Water by the Ruthenium Blue Dimer. J. Phys. Chem. A 2011, 115, 8003-8016. 11. Zhang, M.; de Respinis, M.; Frei, H. Time-resolved observations of water oxidation intermediates on a cobalt oxide nanoparticle catalyst. Nat. Chem. 2014, 6, 362-7.

12. Zhang, M.; Frei, H. Towards a Molecular Level Understanding of the Multi-Electron Catalysis of Water Oxidation on Metal Oxide Surfaces. Catal. Lett. 2015, 145, 420-435. 
13. Concepcion, J. J.; Jurss, J. W.; Templeton, J. L.; Meyer, T. J. One Site is Enough. Catalytic Water Oxidation by [Ru(tpy)(bpm)(OH2)]2+ and [Ru(tpy)(bpz)(OH2)]2+. J. Am. Chem. Soc. 2008, 130, 16462-16463.

14. Chen, Z.; Concepcion, J. J.; Hu, X.; Yang, W.; Hoertz, P. G.; Meyer, T. J. Concerted O atom-proton transfer in the $\mathrm{O}-\mathrm{O}$ bond forming step in water oxidation. Proc. Natl. Acad. Sci. U. S. A. 2010, 107, 7225-7229.

15. Tseng, H.-W.; Zong, R.; Muckerman, J. T.; Thummel, R. Mononuclear Ruthenium(II) Complexes That Catalyze Water Oxidation. Inorg. Chem. 2008, 47, 11763-11773.

16. Lin, X.; Hu, X.; Concepcion, J. J.; Chen, Z.; Liu, S.; Meyer, T. J.; Yang, W. Theoretical study of catalytic mechanism for single-site water oxidation process. Proc. Natl. Acad. Sci. U. S. A. 2012, 109, 15669-15672.

17. Concepcion, J. J.; Tsai, M.-K.; Muckerman, J. T.; Meyer, T. J. Mechanism of Water Oxidation by Single-Site Ruthenium Complex Catalysts. J. Am. Chem. Soc. 2010, 132, 15451557.

18. Vannucci, A. K.; Alibabaei, L.; Losego, M. D.; Concepcion, J. J.; Kalanyan, B.; Parsons, G. N.; Meyer, T. J. Crossing the divide between homogeneous and heterogeneous catalysis in water oxidation. Proc. Natl. Acad. Sci. U. S. A. 2013, 110, 20918-20922.

19. Xie, Y.; Shaffer, D. W.; Lewandowska-Andralojc, A.; Szalda, D. J.; Concepcion, J. J. Water Oxidation by Ruthenium Complexes Incorporating Multifunctional Bipyridyl Diphosphonate Ligands. Angew. Chem., Int. Ed. 2016, 55, 8067-8071.

20. Romain, S.; Bozoglian, F.; Sala, X.; Llobet, A. Oxygen-Oxygen Bond Formation by the Ru-Hbpp Water Oxidation Catalyst Occurs Solely via an Intramolecular Reaction Pathway. $J$. Am. Chem. Soc. 2009, 131, 2768-2769.

21. Ullman, A. M.; Brodsky, C. N.; Li, N.; Zheng, S.-L.; Nocera, D. G. Probing Edge Site Reactivity of Oxidic Cobalt Water Oxidation Catalysts. J. Am. Chem. Soc. 2016, 138, 42294236.

22. Koroidov, S.; Anderlund, M. F.; Styring, S.; Thapper, A.; Messinger, J. First turnover analysis of water-oxidation catalyzed by Co-oxide nanoparticles. Energy Environ. Sci. 2015, 8, 2492-2503.

23. Duan, L.; Wang, L.; Li, F.; Li, F.; Sun, L. Highly Efficient Bioinspired Molecular Ru Water Oxidation Catalysts with Negatively Charged Backbone Ligands. Acc. Chem. Res. 2015, 48, 2084-2096.

24. Blakemore, J. D.; Crabtree, R. H.; Brudvig, G. W. Molecular Catalysts for Water Oxidation. Chem. Rev. 2015, 115, 12974-13005.

25. Zeng, Q.; Lewis, F. W.; Harwood, L. M.; Hartl, F. Role of ligands in catalytic water oxidation by mononuclear ruthenium complexes. Coord. Chem. Rev. 2015, 304-305, 88-101. 26. Concepcion, J. J.; Jurss, J. W.; Brennaman, M. K.; Hoertz, P. G.; Patrocinio, A. O. T.; Murakami Iha, N. Y.; Templeton, J. L.; Meyer, T. J. Making Oxygen with Ruthenium Complexes. Acc. Chem. Res. 2009, 42, 1954-1965.

27. Duan, L.; Fischer, A.; Xu, Y.; Sun, L. Isolated Seven-Coordinate Ru(IV) Dimer Complex with $[\mathrm{HOHOH}]-$ Bridging Ligand as an Intermediate for Catalytic Water Oxidation. J. Am. Chem. Soc. 2009, 131, 10397-10399.

28. Duan, L.; Bozoglian, F.; Mandal, S.; Stewart, B.; Privalov, T.; Llobet, A.; Sun, L. A molecular ruthenium catalyst with water-oxidation activity comparable to that of photosystem II. Nat. Chem. 2012, 4, 418-423. 
29. Richmond, C. J.; Matheu, R.; Poater, A.; Falivene, L.; Benet-Buchholz, J.; Sala, X.; Cavallo, L.; Llobet, A. Supramolecular Water Oxidation with Ru-bda-Based Catalysts. Chem. Eur. J. 2014, 20, 17282-17286.

30. Song, N.; Concepcion, J. J.; Binstead, R. A.; Rudd, J. A.; Vannucci, A. K.; Dares, C. J.; Coggins, M. K.; Meyer, T. J. Base-enhanced catalytic water oxidation by a carboxylatebipyridine Ru(II) complex. Proc. Natl. Acad. Sci. U. S. A. 2015, 112, 4935-4940.

31. Sheridan, M. V.; Sherman, B. D.; Fang, Z.; Wee, K.-R.; Coggins, M. K.; Meyer, T. J. Electron Transfer Mediator Effects in the Oxidative Activation of a Ruthenium Dicarboxylate Water Oxidation Catalyst. ACS Catal. 2015, 5, 4404-4409.

32. Sheridan, M. V.; Sherman, B. D.; Marquard, S. L.; Fang, Z.; Ashford, D. L.; Wee, K.-R.; Gold, A. S.; Alibabaei, L.; Rudd, J. A.; Coggins, M. K.; Meyer, T. J. Electron Transfer Mediator Effects in Water Oxidation Catalysis by Solution and Surface-Bound Ruthenium BpyDicarboxylate Complexes. J. Phys. Chem. C 2015, 119, 25420-25428.

33. Concepcion, J. J.; Zhong, D. K.; Szalda, D. J.; Muckerman, J. T.; Fujita, E. Mechanism of water oxidation by [Ru(bda)(L)2]: the return of the "blue dimer". Chem. Commun. 2015, 51, 4105-4108.

34. Matheu, R.; Francàs, L.; Chernev, P.; Ertem, M. Z.; Batista, V.; Haumann, M.; Sala, X.; Llobet, A. Behavior of the Ru-bda Water Oxidation Catalyst Covalently Anchored on Glassy Carbon Electrodes. ACS Catal. 2015, 5, 3422-3429.

35. Matheu, R.; Ertem, M. Z.; Benet-Buchholz, J.; Coronado, E.; Batista, V. S.; Sala, X.; Llobet, A. Intramolecular Proton Transfer Boosts Water Oxidation Catalyzed by a Ru Complex. J. Am. Chem. Soc. 2015, 137, 10786-10795.

36. Rabten, W.; Kärkäs, M. D.; Åkermark, T.; Chen, H.; Liao, R.-Z.; Tinnis, F.; Sun, J.; Siegbahn, P. E. M.; Andersson, P. G.; Åkermark, B. Catalytic Water Oxidation by a Molecular Ruthenium Complex: Unexpected Generation of a Single-Site Water Oxidation Catalyst. Inorg. Chem. 2015, 54, 4611-4620.

37. Sander, A. C.; Maji, S.; Francàs, L.; Böhnisch, T.; Dechert, S.; Llobet, A.; Meyer, F. Highly Efficient Binuclear Ruthenium Catalyst for Water Oxidation. ChemSusChem 2015, 8, 1697-1702.

38. $\quad$ Tong, L.; Inge, A. K.; Duan, L.; Wang, L.; Zou, X.; Sun, L. Catalytic Water Oxidation by Mononuclear Ru Complexes with an Anionic Ancillary Ligand. Inorg. Chem. 2013, 52, 25052518.

39. Tong, L.; Wang, Y.; Duan, L.; Xu, Y.; Cheng, X.; Fischer, A.; Ahlquist, M. S. G.; Sun, L. Water Oxidation Catalysis: Influence of Anionic Ligands upon the Redox Properties and Catalytic Performance of Mononuclear Ruthenium Complexes. Inorg. Chem. 2012, 51, 33883398.

40. Duan, L.; Wang, L.; Inge, A. K.; Fischer, A.; Zou, X.; Sun, L. Insights into Ru-Based Molecular Water Oxidation Catalysts: Electronic and Noncovalent-Interaction Effects on Their Catalytic Activities. Inorg. Chem. 2013, 52, 7844-7852.

41. Jiang, Y.; Li, F.; Huang, F.; Zhang, B.; Sun, L. Chemical and photocatalytic water oxidation by mononuclear Ru catalysts. Chin. J. Catal. 2013, 34, 1489-1495.

42. Sato, Y.; Takizawa, S.-y.; Murata, S. Substituent Effects on Physical Properties and Catalytic Activities toward Water Oxidation in Mononuclear Ruthenium Complexes. Eur. J. Inorg. Chem. 2015, 2015, 5495-5502. 
43. Li, T.-T.; Zhao, W.-L.; Chen, Y.; Li, F.-M.; Wang, C.-J.; Tian, Y.-H.; Fu, W.-F. Photochemical, Electrochemical, and Photoelectrochemical Water Oxidation Catalyzed by Water-Soluble Mononuclear Ruthenium Complexes. Chem. - Eur. J. 2014, 20, 13957-13964.

44. Liu, Z.; Gao, Y.; Yu, Z.; Zhang, M.; Liu, J. Effects of Br substituent on catalytic performance of Ru-bda (H2bda = 2,2'-bipyridine-6,6'-dicarboxylic acid) catalysts for water oxidation. Chin. J. Catal. 2015, 36, 1742-1749.

45. Wasylenko, D. J.; Ganesamoorthy, C.; Koivisto, B. D.; Henderson, M. A.; Berlinguette, C. P. Insight into Water Oxidation by Mononuclear Polypyridyl Ru Catalysts. Inorg. Chem. 2010, 49, 2202-2209.

46. Li, F.; Jiang, Y.; Zhang, B.; Huang, F.; Gao, Y.; Sun, L. Towards A Solar Fuel Device: Light-Driven Water Oxidation Catalyzed by a Supramolecular Assembly. Angew. Chem., Int. Ed. 2012, 51, 2417-2420.

47. Vlád, G.; Horváth, I. T. Improved Synthesis of 2,2‘-Bipyrimidine. J. Org. Chem. 2002, 67, 6550-6552.

48. Benson, E. E.; Grice, K. A.; Smieja, J. M.; Kubiak, C. P. Structural and spectroscopic studies of reduced $[\mathrm{Re}(\mathrm{bpy}-\mathrm{R})(\mathrm{CO}) 3]-1$ species relevant to $\mathrm{CO} 2$ reduction. Polyhedron 2013, $58,229-234$.

49. Donnici, C. L.; Filho, D. H. M.; Moreira, L. L. C.; Reis, G. T. d.; Cordeiro, E. S.; Oliveira, I. M. F. d.; Carvalho, S.; Paniago, E. B. Synthesis of the Novel 4,4'- and 6,6'Dihydroxamic - 2,2'-Bipyridines and Improved Routes to 4,4'- and 6,6'- Substituted 2,2'Bipyridines and Mono-N-Oxide-2,2'-Bipyridine. J. Braz. Chem. Soc. 1998, 9, 455-460.

50. Guden-Silber, T.; Klein, K.; Seitz, M. 4,4[prime or minute]-Bis(trifluoromethyl)2,2[prime or minute]-bipyridine - a multipurpose ligand scaffold for lanthanoid-based luminescence/19F NMR probes. Dalton Trans. 2013, 42, 13882-13888.

51. Puglisi, A.; Benaglia, M.; Roncan, G. Palladium-Catalyzed Synthesis of Nonsymmetrically Functionalized Bipyridines, Poly(bipyridines) and Terpyridines. Eur. J. Org. Chem. 2003, 1552-1558.

52. Shin, D.; Switzer, C. A metallo base-pair incorporating a terpyridyl-like motif: bipyridylpyrimidinone[middle dot]Ag(i)[middle dot]4-pyridine. Chem. Commun. 2007, 4401-4403.

53. Freedman, D. A.; Evju, J. K.; Pomije, M. K.; Mann, K. R. Convenient Synthesis of TrisHeteroleptic Ruthenium(II) Polypyridyl Complexes. Inorg. Chem. 2001, 40, 5711-5715.

54. Norris, M. R.; Concepcion, J. J.; Glasson, C. R. K.; Fang, Z.; Lapides, A. M.; Ashford, D. L.; Templeton, J. L.; Meyer, T. J. Synthesis of Phosphonic Acid Derivatized Bipyridine Ligands and Their Ruthenium Complexes. Inorg. Chem. 2013, 52, 12492-12501.

55. Małecki, J. G.; Jaworska, M.; Kruszynski, R.; Gil-bortnowska, R. Synthesis and characterization of [RuCl2(picoline)4] complexes: Crystal structure of [RuCl2( $\beta$-pic 4$]$. Polyhedron 2005, 24, 1445-1453.

56. In the ruthenium(II) oxidation state, an acetonitrile molecule displaces one arm of of the R-bda ligand. Upon oxidation to ruthenium(III), the acetonitrile is lost in favor of a water molecule. See references 30 and 40. This results in higher II/III oxidation potentials than those reported in non-binding solvents, as shown in reference 30.

57. Duan, L.; Xu, Y.; Zhang, P.; Wang, M.; Sun, L. Visible Light-Driven Water Oxidation by a Molecular Ruthenium Catalyst in Homogeneous System. Inorg. Chem. 2010, 49, 209-215.

58. Chen, Z.; Vannucci, A. K.; Concepcion, J. J.; Jurss, J. W.; Meyer, T. J. Proton-coupled electron transfer at modified electrodes by multiple pathways. Proc. Natl. Acad. Sci. U. S. A.

2011, 108, E1461-E1469. 
59. Wang, L.; Duan, L.; Stewart, B.; Pu, M.; Liu, J.; Privalov, T.; Sun, L. Toward Controlling Water Oxidation Catalysis: Tunable Activity of Ruthenium Complexes with Axial Imidazole/DMSO Ligands. J. Am. Chem. Soc. 2012, 134, 18868-18880.

60. At concenctrations approaching $100 \mathrm{nM}$, the lifetime of the catalyst was not suffient to provide accurate fits for kinetic data.

61. Duan, L.; Bozoglian, F.; Mandal, S.; Stewart, B.; Privalov, T.; Llobet, A.; Sun, L. A molecular ruthenium catalyst with water-oxidation activity comparable to that of photosystem II. Nat Chem 2012, 4, 418-423.

62. Tsubonouchi, Y.; Lin, S.; Parent, A. R.; Brudvig, G. W.; Sakai, K. Light-induced water oxidation catalyzed by an oxido-bridged triruthenium complex with a Ru-O-Ru-O-Ru motif. Chem. Commun. 2016, 52, 8018-8021.

63. Zhang, B.; Li, F.; Zhang, R.; Ma, C.-B.; Chen, L.; Sun, L. Characterization of a Trinuclear Ruthenium Intermediate in Catalytic Water Oxidation by Ru(bda)(pic)2 in Neutral Media. Chem. Commun. 2016, 52, 8619-8622.

64. Liu, Z.; Gao, Y.; Zhang, M.; Liu, J. Design of a dinuclear ruthenium based catalyst with a rigid xanthene bridge for catalytic water oxidation. Inorg. Chem. Commun. 2015, 55, 56-59.

65. Jiang, Y.; Li, F.; Zhang, B.; Li, X.; Wang, X.; Huang, F.; Sun, L. Promoting the Activity of Catalysts for the Oxidation of Water with Bridged Dinuclear Ruthenium Complexes. Angew. Chem., Int. Ed. 2013, 52, 3398-3401.

66. Zhang, L.; Gao, Y.; Ding, X.; Yu, Z.; Sun, L. High-Performance Photoelectrochemical Cells Based on a Binuclear Ruthenium Catalyst for Visible-Light-Driven Water Oxidation. ChemSusChem 2014, 7, 2801-2804.

67. Zhang, L. L.; Gao, Y.; Liu, Z.; Ding, X.; Yu, Z.; Sun, L. C. A trinuclear ruthenium complex as a highly efficient molecular catalyst for water oxidation. Dalton Trans. 2016, 45, 3814-3819.

68. Wasylenko, D. J.; Ganesamoorthy, C.; Henderson, M. A.; Berlinguette, C. P. Unraveling the Roles of the Acid Medium, Experimental Probes, and Terminal Oxidant, (NH4)2[Ce(NO3)6], in the Study of a Homogeneous Water Oxidation Catalyst. Inorg. Chem. 2011, 50, 3662-3672.

69. Codolà, Z.; Gómez, L.; Kleespies, S. T.; Que Jr, L.; Costas, M.; Lloret-Fillol, J. Evidence for an oxygen evolving iron-oxo-cerium intermediate in iron-catalysed water oxidation. Nat. Commun. 2015, 6, 5865.

70. Pokhrel, R.; Goetz, M. K.; Shaner, S. E.; Wu, X.; Stahl, S. S. The “Best Catalyst” for Water Oxidation Depends on the Oxidation Method Employed: A Case Study of Manganese Oxides. J. Am. Chem. Soc. 2015, 137, 8384-8387.

71. Bennett, M. A.; Smith, A. K. Arene ruthenium(II) complexes formed by dehydrogenation of cyclohexadienes with ruthenium(III) trichloride. J. Chem. Soc., Dalton Trans. 1974, 233-241. 72. Harris, R. K.; Becker, E. D.; Cabral de Menezes, S. M.; Goodfellow, R.; Granger, P. NMR nomenclature. Nuclear spin properties and conventions for chemical shifts (IUPAC Recommendations 2001). Pure Appl. Chem. 2001, 73, 1795-1818.

73. Juris, A.; Balzani, V.; Barigelletti, F.; Campagna, S.; Belser, P.; von Zelewsky, A. Ru(II) polypyridine complexes: photophysics, photochemistry, eletrochemistry, and chemiluminescence. Coord. Chem. Rev. 1988, 84, 85-277. 
For Table of Contents Only:

Water oxidation catalysis by series of $(\mathrm{R}-\mathrm{bda}) \mathrm{Ru}(\mathrm{L})_{2}$ water oxidation catalysts, including new variants with one and two trifluoromethyl groups in the 4- positions of the bda ${ }^{2-}$ ligand, was studied by electrochemical and stopped-flow kinetics. The rate-limiting step varied with catalyst concentration, with an oxidation step being limiting at higher concentrations (rate = $\mathrm{k}_{1,1}[\mathrm{Ru}]\left[\mathrm{Ce}^{\mathrm{IV}}\right]$ ) and a bimolecular coupling being limiting at lower concentrations (rate = $\left.\mathrm{k}_{2,0}[\mathrm{Ru}]^{2}\right)$. The effects of $\mathrm{bda}^{2-}$ substituents and axial ligands are assessed.

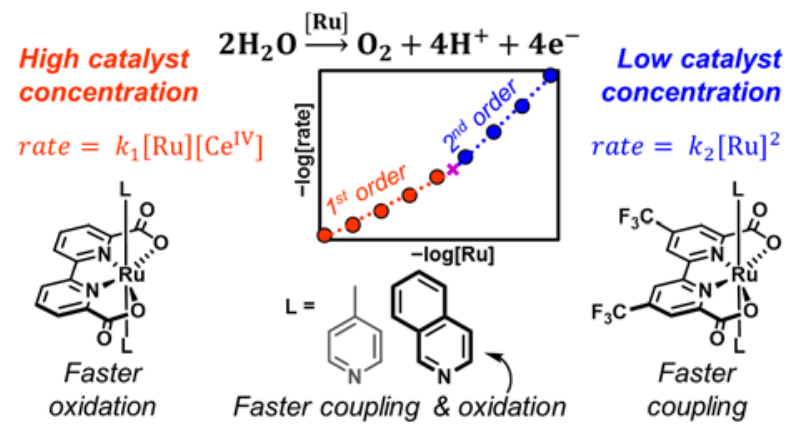

